\title{
New perspectives in cancer biology from a study of canonical and non-canonical functions of base excision repair proteins with a focus on early steps
}

\author{
Matilde Clarissa Malfatti, Giulia Antoniali, Marta Codrich, Silvia Burra, \\ Giovanna Mangiapane, Emiliano Dalla ${ }^{\circ}$ and Gianluca Tell*,
}

Laboratory of Molecular Biology and DNA repair, Department of Medicine (DAME), University of Udine, Piazzale M. Kolbe 4, 33100 Udine, Italy

*To whom correspondence should be addressed. Tel: +39 0432 494311; Fax: +39 0432 494301; Email: gianluca.tell@uniud.it

Received 16 May 2019; Editorial decision 29 November 2019; Accepted 5 December 2019.

\begin{abstract}
Alterations of DNA repair enzymes and consequential triggering of aberrant DNA damage response (DDR) pathways are thought to play a pivotal role in genomic instabilities associated with cancer development, and are further thought to be important predictive biomarkers for therapy using the synthetic lethality paradigm. However, novel unpredicted perspectives are emerging from the identification of several non-canonical roles of DNA repair enzymes, particularly in gene expression regulation, by different molecular mechanisms, such as (i) non-coding RNA regulation of tumour suppressors, (ii) epigenetic and transcriptional regulation of genes involved in genotoxic responses and (iii) paracrine effects of secreted DNA repair enzymes triggering the cell senescence phenotype. The base excision repair (BER) pathway, canonically involved in the repair of non-distorting DNA lesions generated by oxidative stress, ionising radiation, alkylation damage and spontaneous or enzymatic deamination of nucleotide bases, represents a paradigm for the multifaceted roles of complex DDR in human cells. This review will focus on what is known about the canonical and non-canonical functions of BER enzymes related to cancer development, highlighting novel opportunities to understand the biology of cancer and representing future perspectives for designing new anticancer strategies. We will specifically focus on APE1 as an example of a pleiotropic and multifunctional BER protein.
\end{abstract}

\section{Introduction}

Tumour cells can develop drug resistance via repair mechanisms that counteract the DNA damage induced by chemo- and radiotherapies. DNA repair enzymes are therefore possible targets for promising and novel anticancer strategies $(1,2)$, in which specific DNA repair inhibitors are combined with DNA-damaging agents to improve current anticancer therapies. In parallel, some cancer cells show a reduced repertoire of DNA damage responses (DDRs), which provide other therapeutic possibilities, relying on the synthetic lethality paradigm. Indeed, many polymorphic variants of DDR enzymes have been described in the whole population, but their causal link with genome instability, associated with tumour development, is still controversial. Emerging evidence in tumour biology has shown that RNA processing pathways participate in DDR, and that defects in these regulatory connections are associated with genomic instability in cancers $(3,4)$. Indeed, many DNA repair proteins interact with proteins involved in RNA metabolism, non-coding RNA (ncRNA) processing and gene transcriptional regulation (5), indicating a substantial role of the deriving interactome network in determining their non-canonical functions, thus impacting gene expression in tumour cells. Moreover, recent studies have shown several interactions among DDR components and microRNAs (miRNAs) and, notably, a dysregulation of the miRNA biogenesis process has been linked 
to cancer development (2). Importantly, the molecular mechanisms of miRNA processing and/or decay during genotoxic stress are still largely unknown, but it is possible that enzymes of the DNA repair pathways may be protagonists. We have recently reported that enzymes of the base excision DNA repair (BER) pathway play a crucial role in these molecular processes $(6,7)$. Due to its function in the maintenance of genome stability under conditions of oxidative stress as well as exposure to DNA damaging agents used in chemotherapy, and its central involvement in transcriptional regulatory circuits, the BER pathway represents an unexpected and intriguing opportunity to identify novel cancer biomarkers and design new anticancer strategies. These findings prompted us to study the role of BER proteins in a different way, to understand their real contribution to the onset of cancer. These findings will help us to better understand the role of these enzymes from benchtop to bedside using a powerful translational perspective. This review will focus on what is known of the canonical (canonical DNA repair of DNA damage) and non-canonical functions (transcriptional, immunological, or repair of RNA-decay/ processing) of BER enzymes, to link these functions with the biology of cancer.

\section{Focus on the canonical roles of the BER pathway in DNA repair and telomere maintenance}

Exposure to endogenous (i.e. mitochondrial respiration and inflammatory processes) or exogenous (i.e. ionising radiation, chemotherapy treatment by alkylating agents and antimetabolites) damaging effectors including deaminating agents, triggers an accumulation of non-bulky single base lesions on both nuclear and mitochondrial DNA $(8,9)$, which can be efficiently repaired by the BER pathway. Thus, this pathway, which is largely conserved from Bacteria to Eukaria, preserves genomic integrity (10). The first enzymatic step in the BER pathway involves lesion-specific DNA glycosylase activity. In mammalian cells, each of the 11 existing $N$-glycosylase proteins differs from the others in its mechanism of action, substrate specificity and excision kinetics (11-13). Generally, the recognition of specific damaged bases occurs through a flipping out mechanism followed by a sophisticated process involving excision of the damaged base (14), thus leaving an abasic (AP) site. DNA glycosylases are classified into mono- and bifunctional glycosylases on the basis of the type of recognised damaged site and on the mechanism of action. Monofunctional DNA glycosylases, e.g. uracil DNA glycosylases (UDG), including the mitochondrial uracil $\mathrm{N}$-glycosylase (UNG1), nuclear UNG2 and a single strand selective monofunctional uracil DNA glycosylase (SMUG1), process uracil, thymine and alkylated bases, to cleave the $\mathrm{C} 1-\mathrm{N}$-glycosidic bond, leaving an AP site and liberating a nucleobase. Bifunctional glycosylases, including the 8-oxo-7,8-dihydroguanine DNA glycosylase (OGG1), NTH1 and the Nei-like DNA glycosylase (NEIL) family, cleave oxidative lesions and display, in addition to their glycosylase activity, an extra AP-lyase activity (15). As already demonstrated by Hill et al. (16) and by our recent work (7), OGG1 activity is stimulated by the presence of APE1 endonuclease, an enzyme that acts following OGG1 during the BER pathway. After the recognition of damage, bifunctional glycosylases use an amine nucleophile, such as a lysine side chain, to cleave the $\mathrm{N}$-glycosidic bond, generating a Schiff base (imine) intermediate (17). Subsequently, through their AP-lyase activity, they cleave the DNA phosphodiester backbone on the $3^{\prime}$ side of the lesion, through a $\beta$-elimination resulting in a single-strand break. Moreover, some of them perform a second cleavage on the
DNA phosphodiester backbone on the $5^{\prime}$ side of the lesion through a $\delta$-elimination process (18). Although the importance of the BER pathway has been clearly demonstrated using BER gene knock-out models, resulting in embryonic or early postnatal lethality (19), it has been reported that a high variety of glycosylases in mammalian cells causes a significant redundancy in their damage selectivity, which would explain why a single knock-out of one of the multiple DNA glycosylases is not always lethal (14).

After the hydrolysis of the $\mathrm{N}$-glycosidic bond by DNA glycosylases, the newly generated AP site must be processed by a specific apurinic/apyrimidinic endonuclease (20). Furthermore, a spontaneous depurination of DNA also occurs very frequently. It has been estimated that, considering only spontaneous hydrolysis of the $\mathrm{N}$-glycosidic bond, up to 10000 abasic sites are formed per day/cell in higher eukaryotes $(21,22)$. Unrepaired abasic sites are mutagenic and lethal for the cell, so it is clear that their repair is imperative (23). In this context, the apurinic/apyrimidinic endonuclease 1 (APE1) is the only enzyme having a role in DNA repair $(24,25)$. Embryonic lethality as a consequence of the deletion of the ape 1 gene highlights the importance of APE1, which is not only restricted to the BER pathway, but is also related to all its physiological cellular functions (26). APE1 is a monomeric protein, structured in a $\alpha / \beta$ sandwich globular fold coupled to a 48-amino acid, unstructured part in the $\mathrm{N}$-terminal portion (27). Through its C-terminal globular region (residues 61-318), mainly responsible for endonuclease activity (28), APE1 specifies the presence of abasic sites among any normal nucleoside, principally distorting the DNA backbone with an $35^{\circ}$-angled extrahelical distortion (29). When the APE1-DNA complex is formed, an additional rearrangement is needed to allow the efficient execution of the hydrolytic reaction. The presence of $\mathrm{Mg}^{2+}\left(\right.$ or $\left.\mathrm{Mn}^{2+}\right)$ ions, positioned in the active site of APE1 and principally coordinated by the E96 residue, is necessary to promote this rearrangement and to allow for cleavage of the AP site (30). The excision of the phosphodiester bond, at the $5^{\prime}$ side of the AP-site, also requires a water molecule acting as a nucleophile (31). The active site of the endonuclease is defined by several residues including His-309, Glu-96, Asp-283, Thr-265, Tyr-171, Asn-68, Asp-210, Asp70 and Asn-212, which are mostly involved in hydrogen bonding (31-33). Through this pocket site, APE1 is also active on damaged single-stranded DNA (ssDNA), suggesting a possible role in transcription, replication and/or recombination (34). Furthermore, in vitro studies have demonstrated the capability of APE1 to act as a $3^{\prime}$ DNA phosphatase and $3^{\prime} \rightarrow 5^{\prime}$ DNA exonuclease on mismatched deoxyribonucleotides located at the $3^{\prime}$-end of nicked or gapped DNA (35-37). Recently, great importance has also been ascribed to the APE1 N-terminal region (1-127 residues), which is responsible for protein-protein interactions, RNA interactions (residues 1-33) and redox-dependent activities (38). Among all the well-known interactions of APE1 (39), nucleophosmin (NPM1) is a paradigmatic example of how APE1 functions may be modulated by protein interacting partners, thus impacting tumour biology (40). As demonstrated in acute myeloid leukemia (AML), cells expressing a nucleolar deficient form of the NPM1 protein (i.e. NPM1c+) have an altered APE1-NPM1 functional interaction with consequential BER impairment $(40,41)$. This finding supports the hypothesis that an alteration of APE1 interactions may be causally involved in cancer development and chemoresistance. Moreover, the $\mathrm{N}$-terminal region of APE1 is also subjected to different post-translational modifications (PTMs) (42). Although its functional relevance is still controversial, the most well-known PTM of APE1 is the cleavage of the first 33 amino acids. This truncated protein lacks the nuclear localisation 
signal sequence, leading to the accumulation of protein within the cytoplasmic compartment, and impairing the ability of the protein to interact with its canonical protein partners, including NPM1. Moreover, it has been clearly shown how the removal of the first 33 amino acids does not affect the APE1 binding affinity for the abasic site, but, in contrast, increases the enzymatic catalysis when compared with the full-length protein $(38,43,44)$. Up to now, the protease responsible for the cleavage is still unknown, even though it has been suggested that a Granzyme-like factor could play a role (45). Beyond the $\mathrm{N}$-terminal cleavage, a well-known in vitro and in vivo PTM of APE1 is represented by acetylation. Different lysine residues, including the lysine 27-35 (K27-K35) cluster could be subjected to acetylation (46). In acetylated (acAPE1), the positive charge of the N-tail of APE1 is neutralised, triggering a conformational change of the whole protein. Thus, acAPE1 is more prone to associate with chromatin, and less prone to interact with NPM1. A decrease of the APE1-NPM1 interaction, as a consequence of APE1 acetylation, determines inhibition of the APE1 accumulation within nucleoli $(44,47)$ and an enhancement of its AP endonuclease activity due to an increase of the speed of product release upon cleavage $(38,46,48)$. The observed effects of the PTMs occurring on the N-tail of APE1 highlight how the N-terminal region may indirectly influence the BER activity of APE1. Currently, the acetylation of APE1 is the main PTM of APE1 detected in vivo, as described in the subsequent paragraphs.

Upon AP cleavage promoted by APE1, a single-strand break bearing a free hydroxyl $(\mathrm{OH})$ group at the $3^{\prime}$ end and a deoxyribose phosphate (dRP) at the $5^{\prime}$ end is generated. In this phase, BER could follow two alternative sub-pathways. In the classical mechanism, also called 'short patch' (SP-BER), polymerase $\beta$ ( $\mathrm{Pol} \beta$ ) replaces the single missing nucleotide, adding the correct one at the $3^{\prime}$ end of the nick. Then, DNA ligase I (Lig I) or a XRCC1-Lig III complex, complete the repair (49). Another sub-pathway of BER exists, called 'long patch' (LP-BER), in which Pol $\beta$, coordinated with polymerase $\delta(\operatorname{Pol} \delta)$, polymerase $\varepsilon(\mathrm{Pol} \varepsilon)$, and the sliding clamp proliferating cell nuclear antigen, synthetise a 2-12 nucleotides strand. The remaining flap is excised by flap endonuclease 1 (FEN1), while the nick is sealed by Lig I (50). Due to its elevated complexity, including the high number of BER factors involved as generated DNA intermediates, different hypothesis have been proposed to explain how the BER pathway steps may proceed in a coordinated way. Specifically, in the 'passing the baton' mechanism proposed by Tainer et al. (33), a coordination among all the BER factors in the passage of the DNA intermediates (BER baton) has been suggested. This model would explain how the cell works to preserve cellular stability, and protect it from the presence of potentially mutagenic DNA intermediates (51). In contrast, in the "BERosome" model, proposed in different studies $(52,53)$, a fine regulation exists among all BER enzymes to coordinate every step of DNA repair. This coordination depends on several PTMs that regulate protein-protein interactions, including pathway cascade signaling, cellular localisation, conformational changes and protein stability $(52,54)$. In this scenario, several other proteins, including p53 and NPM1, act as BER modulators $(55,56)$. The efficiency of BER is also due to the coordinated use of additional scaffold proteins. Among them, the poly (ADP-ribose) polymerase 1 assumes an important role in the regulation of BER enzymes. Recent reports have shown the AP lyase activity of poly(ADP-ribose) polymerase 1 (PARP1) (57), and the stimulating activity of PARP1 on APE1 endonuclease activity (58).

Since knock-out of DNA glycosylases does not increase sensitivity to oxidative stress or ionising radiations (59-61), the existence of a backup mechanism acting on damaged bases, typically recognised by BER proteins, has been suggested. In this context, a pathway known as nucleotide incision repair (NIR), acts directly on the $5^{\prime}$ side of the oxidised base by the direct action of APE1, thus ensuring the correct removal of the oxidised bases (62-67), which bypasses the action of glycosylases (Figure 1). The 3' $\mathrm{OH}$ terminals, thus generated, are processed by FEN1 $(68,69)$ and DNA polymerases. Several studies have reported this non-canonical APE1 activity operating in NIR, pointing to substrates that are efficiently processed, which include 5,6-dihydro-2'-deoxyuridine (DHU), 5,6-dihydrothymidine, 5 -hydroxy-2'-deoxyuridine (62,70), 5-hydroxy-2'-deoxycitidine (5OHC) $(62,66,70)$ and alpha-2'-deoxynucleosides $(\alpha \mathrm{dA}, \alpha \mathrm{dT}$ and $\alpha \mathrm{dC})(62,71)$. Notably, the majority of these damages are generated as a consequence of DNA exposure to ionising radiation (72-75). APE1 NIR activity is stimulated under significantly different experimental conditions, in terms of salts, $\mathrm{pH}$ and structural requirements (62), compared with the classical BER activity. Notably, although the N-terminal region of APE1 is indirectly involved in the regulation of BER endonuclease activity, it is essential for the NIR process (62). Timofeyeva et al. (63) have reported how the lysine residue at position 98 (K98) significantly contributes to the $5^{\prime}$ phosphodiester bond hydrolysis of the DNA substrate, but not to the dissociation of the enzyme from the product complex. Furthermore, an amino acid substitution of K98 influences the NIR activity more than the BER activity, demonstrating how the catalytic site active in BER and NIR is the same, although different conformations of APE1 are responsible for the incision of unrelated lesions such as AP sites and DHU, which are substrates of BER and NIR, respectively (63).

A good and well-characterised example of canonical activity of BER in the maintenance of genomic stability is represented by its activity at telomeres. Telomeres are composed of a repetitive non-coding DNA sequence that avoids the loss of genetic information, as the DNA polymerase is generally able to replicate the template DNA until its end, but only on the leading strand (76). In humans, the telomeric sequence is represented by repetitive "TTAGGG" hexameric blocks (77). Human telomeres are bound by the shelterin complex, which is composed of several protein partners that ensure stability and protection to the chromosome ends (78). The shelterin complex also functions to guarantee the acquisition and maintenance of G4 folding (79). This secondary structure is preserved by the establishment of Hoogsten hydrogen bonds between the G4 guanines (80). Because guanine is the base with the lowest redox potential, telomeres are hotspots for oxidative modifications with the consequential generation of 8-oxo-2'-deoxyguanosine (8-oxo-dG) (81), efficiently handled by the BER pathway to be removed and replaced. G4-8-oxo-dG sites are specifically recognised by the NEIL1 and NEIL3 glycosylases (82), which are able to cleave the oxidised base, leaving an abasic site that is then nicked by APE1 (83) (Figure 1). It has been shown that NEIL1 and NEIL 3 process 8-oxo-dG located in G4 structures formed in the promoter region of VEGF and $c$-Myc (83). Regarding 8-oxo-dG generated in G4 structures at telomeric regions, only NEIL3 seems to be able to efficiently cleave it and subsequently recruits the LP-BER machinery to favor repair (84). Moreover, NEIL3 also interacts with the TRF1 shelterin complex, and seems to play an essential role in coordinating the repair of oxidation damages, as demonstrated by telomere dysfunction observed in the absence of this glycosylase (84). Wallace et al. hypothesised the possible involvement of NEIL glycosylases in both telomere maintenance and gene regulation (84). The abasic site generated by glycosylase is later handled by APE1 endonuclease, which is able to bind and process different types of G4, through the involvement of its acetylated lysine residues (i.e. K27-35 cluster) (48) 


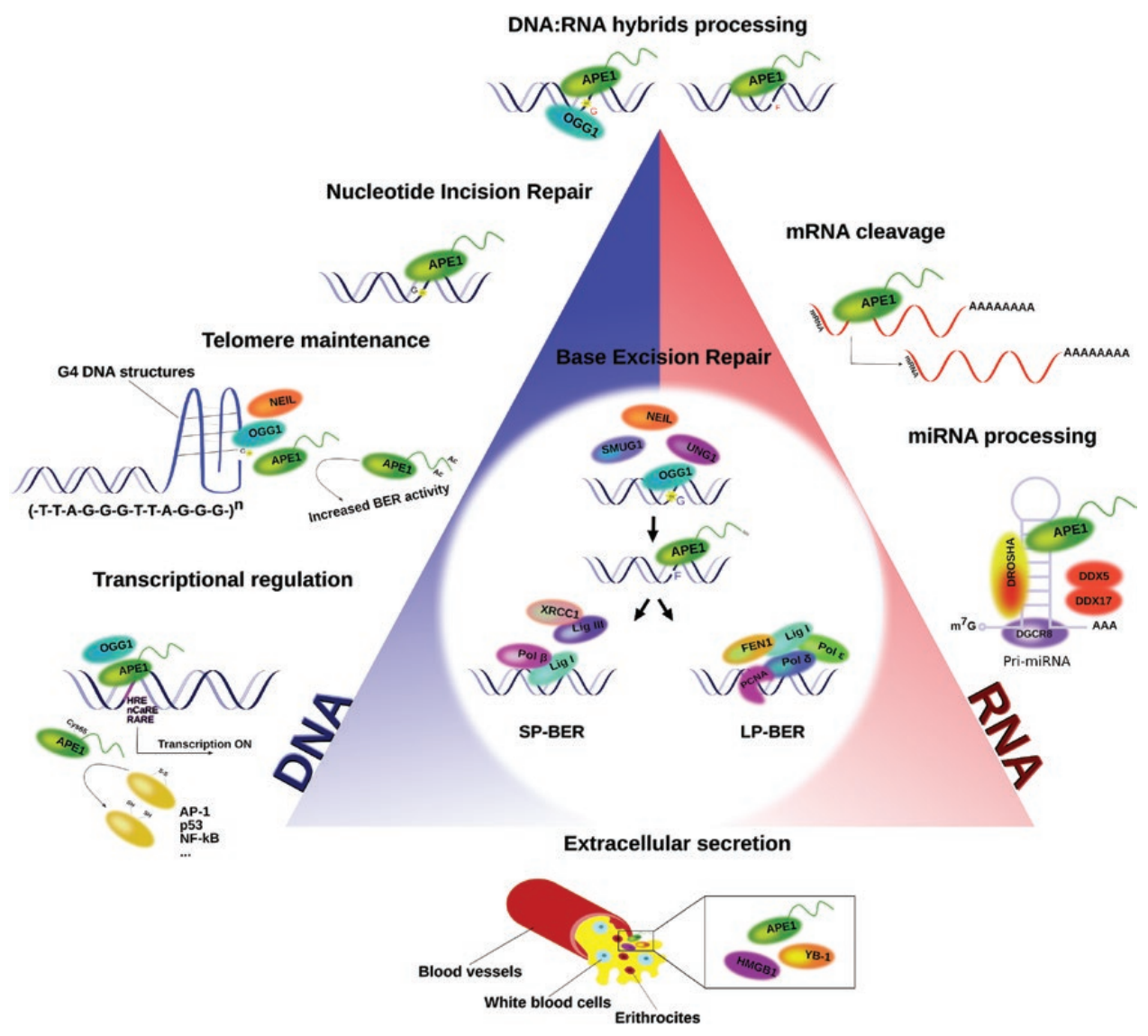

Figure 1. BER pathway and the 'Deathly Allows'. Representational cartoon of canonical and non-canonical functions of enzymes belonging to the BER pathway. In the middle, canonical BER is represented as starting by the action of several glycosylases on non-bulky lesions (8-oxo-dG). When the abasic site (F) is generated, APE1 cleaves it, generating a single-strand break that can be processed by a short- (SP-BER) and long- (LP-BER) patch. Several BER enzymes are also involved in other important cellular pathways regarding DNA processing (left blue side), including a NIR pathway, telomere maintenance and transcriptional regulation. Recently, new discoveries regarding a role of BER enzymes in RNA processing (right red side) are emerging, including mRNA and miRNA processing and/or decay. Moreover, BER enzymes are also involved in the processing of DNA:RNA hybrids, including 8-oxo-G and ribose monophosphate abasic site embedded in DNA (top). Finally, their extracellular secretion has been also recently hypothesised (bottom). See the text for further information. Figure available in colour online.

(Figure 1). The localisation of the abasic site in the quadruplex and the electrostatic interactions that mediate the contact of nucleic acids with APE1 then influence its activity on the lesion (48). The N-terminal region of APE1, and more specifically the lysine residues located in this region, are important for the regulation of the endonuclease activity on G4-containing abasic sites (56). Specifically, APE1 mutants, which mimic the acetylation of lysine residues, display increased endonuclease activity in vitro. The acetylation may therefore represent a dynamic mechanism to fine tune the activity of the protein at telomeric sites (48) (Figure 1). Cells depleted in APE1 showed reduced telomere length and the knock-out of APE1, in postnatal mice, resulted in compromised development and growth, and increased senescence (85). APE1 can also interact with the TRF2 and POT1 sheltering proteins, and its presence at telomeric sites is important in stabilising these regions (86). Moreover, the depletion of APE1 results in telomere dysfunction and segregation defects in cells that employ alternative lengthening of telomere pathways or telomerase re-expression to elongate telomeres (86). These results suggest an interdependence between the BER machinery and telomere homeostasis.

\section{Non-canonical roles of the BER pathway in the immunological response}

The BER pathway, besides being the main mechanism for coping with DNA lesions described above, plays an essential role in the immunological response. It has been clearly shown that BER enzymes regulate the genomic rearrangement that induces the antigenstimulated somatic hypermutation (SHM) process, responsible for the diversification of the variable genomic regions of the heavy and light chains of immunoglobulins, and plays a central function in the process of class switch recombination (CSR) responsible for diversification of the heavy chain constant region (87). These two antibody maturation mechanisms are dependent on the activation-induced cytidine deaminase (AID), which converts cytosine to uracil in the variable $(\mathrm{V})$ and switch $(\mathrm{S})$ regions of the immunoglobulin gene. APE1, through its AP-endonuclease activity, is responsible for the introduction of DNA nicks when AID-dependent deaminated cytidine is removed by the glycosylase, UNG2-dependent BER. Despite several uracil glycosylases being present in mammals, APE1 is the only AP-endonuclease, although a weak endonuclease activity has been recently identified for APE2 (88-90). Besides APE1 and UNG2, all the other BER enzymes have been found to participate in the uracil removal process (91). Their role in SHM and CSR strongly depends on crosstalk between each protein partner, and is finely tuned by the expression levels of each partner and by specific regulated posttranslational modifications, such as phosphorylation of Ser38 in the AID protein $(92,93)$. In particular, while APE1 endonuclease activity is important for CSR, it has been shown to be dispensable for SHM- and AID-induced DNA breaks. In fact, APE1 does not contribute to DNA cleavage through processing of AP sites, but 
rather, it may function as a DNA end-processing enzyme to facilitate the joining of broken ends during CSR $(94,95)$. APE1 endonuclease activity is likely to remove 3'-tyrosyl residues from the DNA end after topoisomerase 1 (Top1) cleavage and Top1-cc degradation, which is essential to efficient recombination of broken $\mathrm{S}$ regions. Additionally, $S$ regions are subjected to a high rate of transcription driven by cytokine-inducible promoters, which regulate the CSR process. Moreover, because APE1 is dispensable for AID activity, understanding the mechanism by which AID is targeted to its substrates is of great interest, given the potentially deleterious consequences of AID's mutagenic activity (96). While the endonuclease activity of APE1 in the CSR process is well-established, its contribution as a transcriptional coactivator has been only hypothesised. In fact, the remaining CSR activity observed in APE1-endonuclease activity deficient cells (88) could be explained by the ability of APE1 to stimulate the DNA-binding activity of several transcription factors, including nuclear factor kappa B (NF- $\mathrm{BB})$ and a few others, involved in inflammation and immunological responses $(6,97,98)$. Very recently, using different APE1 inhibitors and APE1 DNA-repair and redox-defective mutants, we provided more evidence in support of this hypothesis, demonstrating that APE1 redox function also plays an important role in regulating CSR through the IL-6 signaling pathway and proper IgA expression (99).

\section{The role of the BER pathway in trascriptional regulation}

A growing list of BER proteins, that were initially thought to exclusively function in DNA repair, are emerging as important in transcription (100). It is perhaps not surprising that these two processes are often coupled, when considering the mutagenic potential of the transcriptional process. DNA lesion repair, in transcriptionally active genes, must be kept under strict control to maintain transcriptional fidelity and genome stability. However, it does not simply involve a preferential repair of the transcribed DNA strand but, as suggested by several findings, a more physically and functionally intertwined crosstalk between the two processes must exist. Importantly, recent studies have generated a substantial body of evidence pointing to a direct function of DNA repair enzymes as coactivators of transcription.

APE1 represents a paradigmatic example of a DNA repair enzyme with a peculiar function as a transcriptional regulator. Indeed, APE1 plays a role in the regulation of expression of human genes in response to oxidative stress conditions by stimulating the DNA binding activity of several transcription factors, such as nuclear factor kappa B (NF- $\mathrm{KB})$, Egr-1, Hif-1 $\alpha$, Nrf1 and STAT3, thus influencing the onset of inflammatory and metastatic processes (97) (Figure 1). Recently, a direct role of APE1 has also been characterised in the transcription of sirtuin 1 (SIRT1) gene, by binding to negative calcium responsive element (nCaRE) sequences present on its promoter demonstrating that BER-mediated DNA repair promotes the initiation of transcription of the SIRT1 gene upon oxidative DNA damage (98) (Figure 1). Paradoxically, it has been shown that programmed DNA single or double strand breaks, with concomitant activation of the DNA damage response, can induce transcription at gene promoters $(101,102)$. Conventionally, DNA modifications (especially oxidation) are widely thought to be harmful for cell stability (103). The only described exceptions, relative to DNA modifications with important regulatory roles, are 5 -methylcytosine and uracil, which are enzymatically generated in DNA under controlled conditions to fulfil crucial regulatory functions as epigenetic marks, or to be involved in antibody diversification (104). The existence of modifications with potential regulatory functions on other bases remains to be investigated. Oxidative DNA modification, as a consequence of the exposure to reactive oxygen species, is very frequent and guanine is the most susceptible targeted base, with 8-oxo-dG as the most common product (105). The distribution of 8 -oxo-dG sites is not random throughout the genome, but occurs more frequently at the promoter region of active genes, thus contributing to transcriptional regulation (106). If not repaired, 8-oxo-dG is moderately mutagenic, causing a $G$ to $T$ transversion mutation that is thought to be responsible for initiating and driving carcinogenesis and neurodegenerative diseases, such as Alzheimer's and Parkinson's diseases (107-109). Recent evidence has highlighted how the repair of 8-oxo-dG by OGG1 is involved in the regulation of transcription, through the action of specific transcription factors, and also in signal transduction. Numerous reports have reported an interplay between DNA repair of 8-oxo-dG and transcription activation, mostly when this modification is found in promoter regions $(98,101,110)$. These studies proposed that the 8-oxo-dG BER-mediated repair may serve as a modulator for transcription efficiency, supporting a growing body of evidence regarding the role of 8 -oxo-dG as an epigenetic-like DNA modification $(102,111)$. The long-standing view has been that 8 -oxo-dG is mutagenic and can negatively impact cellular processes such as transcription. When 8 -oxo-dG is present in the template strand, it can slightly inhibit the advancement of RNA polymerase II (112), and the initiation of 8-oxo-dG repair may cause polymerases to stop (113); furthermore, the presence of 8 -oxo-dG in transcription binding sites can negatively affect the transcription factor binding activity (114116). For all these reasons, it is thought that 8-oxo-dG may act as a negative signal for transcription. However, there are a few notable findings showing that 8 -oxo-dG, when recognised by OGG1, provides a platform for the coordination of the initial steps of the BER pathway repair coupled with the assembly of the transcriptional machinery to prompt the expression of redox-regulated genes. In particular, the presence of 8 -oxo-dG in promoters can increase gene transcription via the BER pathway; these are well-documented cases of the BCL2 apoptosis regulator (B-cell lymphoma 2) (117), SIRT1 (98), vascular endothelial growth factor (VEGF) $(118,119)$ and tumour necrosis factor-alpha (TNF $\alpha)(110)$ gene expression. We previously proposed that BER-mediated repair of an oxidised guanines at nCaRE sequences is a key event for SIRT1 transcription (98). We hypothesised that the nick, introduced by APE1 during DNA repair, might favor local topological relaxation, facilitating the recruitment of RNA polymerase for gene transcriptional activation. A similar mechanism of transcriptional activation was described later by Pastukh et al. (118), in the context of the VEGF gene, and by Boldogh et al., who demonstrated OGG1 recruitment and upregulation of proinflammatory genes upon TNF $\alpha$-induced oxidation of $\mathrm{G}$ in NF- $\mathrm{KB}$ consensus sequences $(110,120)$. Of note, this reported role of 8-oxo-dG and OGG1 in the activation of inflammatory genes could explain the documented immune deficiencies observed in $\mathrm{OGG}^{-/-}$mice $(121,122)$. Furthermore, using 8-oxo-dG sitespecifically synthesised reporters of the VEGF regulatory sequence, Burrows and co-workers have further characterised the mechanism of coupling BER and transcriptional activation. In particular, they suggested that the presence of 8-oxo-dG in DNA could provide a gene for up/down regulation depending on the strand context. Specifically, they demonstrated that the activation of VEGF transcription depended on the oxidation of Gs present in the guaninerich potential G-quadruplex (G4)-forming sequence (PSQ). Their 
model proposed that when 8-oxo-dG is present in the coding strand of the VEGF PSQ promoter, the produced AP site favors the prolonged stalling of APE1, leading to its inability to cleave in the G4 context but allowing the recruitment of the transcriptional activating machinery for gene induction. In contrast, the presence of 8-oxo-dG on the template strand activates the transcription-coupled nucleotide excision repair pathway, which attenuates transcription $(101,119)$. Very recently, the same group reported a similar mechanism of action for the G-rich potential Z-DNA forming sequences (PZS) (123). This concept has also been shown for other promoters such as that of the endonuclease III-like protein 1 (NTHL1) (101), RAD17 (124), proliferating cell nuclear antigen (PCNA) (125) and NEIL3 (126), which expanded the generalisation of this model mechanism and emphasised the importance of G4-fold oxidation as a critical driver for gene activation. Secondary structures are key elements in the regulation of transcription, because the frequency of potential G4 forming sequences within gene promoters is 1.8 -fold higher if compared with other randomly considered regions (127). In addition, the GC-content positively correlates with transcriptional activity of genes (128), further supporting the possibility that oxidation of $G$ and BER activities have the potential to trigger gene expression. However, the selective induction of 8-oxo-dG in promoter sequences, described in the abovementioned studies, appears difficult to explain as a consequence of general oxidative stress. Perillo et al. (117) suggested an intriguing hypothesis involving a possible alternative explanation for the generation of oxidised bases localised in promoter regions. They showed that lysine specific histone demethylase (LSD1) accounted for the generation of 8-oxo-dG in the estrogen-responsive promoter region of the $b c l-2$ gene. By an oxidative process that releases $\mathrm{H}_{2} \mathrm{O}_{2}$, LSD1 promotes the demethylation of histone $\mathrm{H} 3$ at lysine 9 , which, in turn, modifies the surrounding DNA and determines the recruitment of OGG1 and topoisomerase IIb to remove damaged DNA bases (129). Finally, another mechanism postulates a specific role for the excision of 8-oxo-dG. Boldogh et al. (130) showed that a stoichiometric complex of OGG1 with its excised substrate modification had a high binding affinity for small GTPases, such as Ras, Rac1 and Rho, and that this binding acted as a guanine exchange factor (GEF), consequently activating downstream cellular signaling. Together, these interesting results highlight an intertwined role between DNA repair and gene transcription, which is a phenomenon gaining more interest. Furthermore, coupling BER with transcriptional activation leads to the hypothesis that oxidative modification of $\mathrm{G}$ to 8 -oxo-dG may have regulatory and possibly epigenetic-like features in cells. G4-forming sequences can especially sense oxidative stress and lead to repression or enhancement of transcription. However, whether 8-oxo-dG is an epigenetic modification is not clear and needs further discussion. Typically, epigenetic marks comprise DNA methylation, histone modification and nucleosome localisation, all of which are products of the activity of specific enzymes that modulate the access of transcription machinery. Conversely, DNA oxidation is efficiently repaired by BER and therefore has never been considered epigenetic, especially because it lacks the heritability from mother to daughter as established for the epigenetic definition. Furthermore, the toxic aspect of 8-oxo-dG cannot be ignored. Therefore, further studies are needed to establish whether this modification can be considered helpful, by facilitating gene expression, or as a process leading to mutagenic potential. It can probably be argued that deviations from the proper response to oxidative stress may be due to the impaired action of BER at oxidised guanines, which in turn might be the etiological link of 8-oxo-dG to several pathologies. This consideration also opens new scenarios to pharmacologically modulate OGG1 and APE1 activity to prevent degenerative diseases associated with oxidative stress, which can be derived by an inaccurate action of the two proteins at oxidised guanines.

\section{The roles of the BER pathway in RNA processing}

In the past few years, a clear picture of the involvement of DNA repair enzymes in specific aspects of RNA metabolism has emerged. In particular, a large cohort of BER enzymes has been implicated in RNA processes, especially linked with quality control towards damaged (i.e. abasic and oxidised) RNA molecules (131-133). BER enzymes typically cope with oxidative modifications occurring on DNA, but increasing evidence has suggested the involvement of the BER pathway as the mechanism of surveillance needed to remove damaged RNA molecules to ensure cell viability (133). Currently, an unequivocal description of how cells may deal with oxidised RNA is still missing. Notably, no known enzyme seems to be devoted to the recognition and removal of abasic or oxidised RNA. However, a quality control mechanism should exist to protect from the negative consequences of unrepaired RNA damage, which could lead to an impairment of protein synthesis and noncoding RNA expression, with deleterious effects on the fate of cells. Therefore, a productive crosstalk between DNA repair enzymes and proteins associated with the RNA processing machinery seems more than reasonable. In this context, among the BER components, APE1 has been the particular focus of attention. Increasing evidence has reinforced the view, suggested by our studies of a role of APE1 as a 'cleansing' factor for damaged oxidised/abasic RNA, and possibly highlighted its unsuspected function in RNA metabolism, thus affecting gene expression $(5,133,134)$ (Figure 1). Initially, the potential involvement of APE1 in RNA biology was mainly based on in vitro findings. In particular, we and others reported that APE1 bound structured RNA molecules (135), cleaved abasic single-stranded RNA (ssRNA), and was involved in RNA-decay, with 3'-RNA phosphatase and 3'-exoribonuclease activities (136). In parallel studies, as the interactome of APE1 has been shown, APE1 interaction with components of the RNA metabolism machinery definitively proved the significance of APE1's role in RNA metabolism in vivo $(6,39)$. Proteomic analyses from our studies showed that the APE1 interactome was mostly comprised of proteins involved in ribosome assembly, regulation of mRNA stability (e.g. HNRNPK, YB-1, NPM1 and PABPC1), RNA splicing (e.g. PRPF19, SNRPB and SRPK1) and ribonucleoprotein complex biogenesis (e.g. RPL11, DDX6 and RPS14) (6). In support of these observations, we recently also showed that APE1 may represent a new hub in RNA-processing, including effects on ncRNAs such as miRNAs (6) (Figure 1). This is consistent with recent studies showing that the cellular response to damage requires not only protein-coding genes, but also a subset of ncRNAs $(14,137,138)$. In fact, activation of DNA damage induces the expression of multiple kinds of ncRNAs, such as miRNAs and the recently discovered DROSHA- and Dicer-dependent RNA, the DSB-induced small RNAs and the long intragenic non-coding RNAs (lncRNAs), which contribute to the fine tuning of damage repair to ensure DNA integrity (4). Numerous studies reported that ncRNAs, in particular miRNAs, were able to regulate the DDR by acting on several sensors of damage (e.g. $\gamma$-H2AX), as well as on crucial signal transducers (e.g. ATM, ATR and DNA-PKcs.) and effectors (CHK1, p53 and p21) (137). However, a bidirectional regulatory pathway exists between ncRNAs and DDR factors. It has been postulated that 
few DDR proteins modulate miRNA post-transcriptional processing by regulating the essential steps of their processing and maturation $(6,137)$. Remarkably, in this context, we recently showed a role for APE1 in pri-miRNA processing and stability via association with the DROSHA-processing complex during genotoxic stress. We showed that APE1 endonuclease activity was required for the processing of miR-221/222 in regulating the expression of the tumour suppressor phosphatase and tensin homolog (PTEN). These results highlight how APE1 regulates gene expression through its direct binding and/ or processing of specific miRNAs contributing to cancer progression (6). It is still unknown whether this mechanism is also involved in chemoresistance in cancer. The majority of studies on ncRNAs in the DNA damage field have so far focused on the role of miRNAs, although a role for lncRNAs has also been reported. They have been described to be induced upon DNA damage and associated with ribonucleoproteins and proteins in chromatin by acting in various ways, including as signals, as decoys, or as scaffolds for these protein complexes leading to the regulation of DDR genes $(137,139)$. At present, nothing is known about a possible interaction between lncRNAs and BER enzymes; however, because the expression of lncRNAs has emerged as a new topic in DNA damage, this relationship cannot be excluded. Preliminary results from our laboratory identified few lncRNAs bound by APE1, which might function together with APE1 in DNA repair and safeguarding genome integrity (G. Antoniali et al., in preparation). In accordance with a new role for APE1 in RNA described so far, depletion of this protein in tumour cells leads to nucleolar defects (140), accumulation of oxidised RNA species as well as pri-miRNAs $(6,56)$, alteration of miRNAs expression, impaired protein synthesis and reduced cell growth (56). All these findings, together with the cytoplasmic accumulation of APE1 in several tumour cell types (141), support a major function of APE1 in RNA-processing/decay. Taking into account these observations, the importance of a better understanding of the role played by the BER enzymes in RNA-related processes becomes essential, especially when considering that some pathologies, including neurological disorders and cancer, are associated with deficiencies to both RNA processing and DNA repair (142). Furthermore, these insights might also explain the complexity that underlies BER involvement in the onset of chemoresistance. In conclusion, further studies unveiling the regulatory mechanisms coordinating the interplay between BER activity and RNA processing will be necessary to understand the complexity of DNA repair programs and, finally, these notions can definitively facilitate the development of new anticancer agents.

\section{The BER pathway as a new player in RNA:DNA hybrid processing}

RNA:DNA hybrids physiologically occur during DNA replication and transcription, telomere elongation, retroviral infection and retro-element mobilisation (143). In eukaryotic cells, RNA:DNA structures are classified in: (i) a configuration in which ssRNA is paired to ssDNA; (ii) a R-loop structure, in which a single DNA strand, belonging to the duplex DNA molecule, is hybridised with ssRNA and finally (iii) an incorporation of a single, or more, ribonucleotide(s) (rNMPs) in genomic DNA (144). Although RNA:DNA hybrids are needed for the successful ending of cellular processes, their persistent presence can induce harmful consequences to genome integrity causing replication fork arrest with replicationtranscription collision and chromosomal breakage repair $(145,146)$. For these reasons, a family of endoribonucleases, called RNase H, process the RNA:DNA hybrids to restore regular genomic stability.
Currently, in-depth studies regarding the incorporation of rNMPs within the DNA have been reported (147). This particular RNA:DNA hybrid structure is one of the most common types of DNA damage because of its high frequency and abundance in the genome of both prokaryotes and eukaryotes (148-151). Different methodologies are under development for the detection of ribonucleotides incorporated in DNA (152-155), but the development of different sophisticated high-throughput sequencing-based approaches (156), including ribose-seq $(149,157)$, hydrolytic end-sequencing (HydEn-seq) (158), polymerase usage sequencing (PU-seq) (159), embedded ribosesequencing (emRibo-seq) (160) and (trimethylsilyl)diazomethane derivatisation followed by liquid chromatography-tandem mass spectrometry (154) analyses have facilitated the discovery of distributions and abundances of rNMPs in genomic DNA. Remarkably, a widespread but nonrandom distribution of rNMPs presenting several hotspots and a preference for rCMPs and rGMPs has been discovered (149). The high frequency (>100 million in mammalian cells) of rNMPs included in the nascent DNA molecule found during each replication cycle and DNA repair could have different origins. An imbalance of the rNTPs:dNTPs ratio, generally in favour of rNTPs in normal conditions $(149,161)$, and an imprecise discriminating capacity of DNA polymerases, which can erroneously incorporate rNTPs rather than dNTPs, are two aspects playing a role in these mechanisms (162-166). Moreover, RNA primers, synthetised to allow DNA lagging strand replication (167), could be considered an additional cause of the presence of rNMPs in DNA. Indeed, if RNA primers are not correctly removed, isolated $\mathrm{rNMP}(\mathrm{s})$ can be included among consecutive Okazaki fragments, which could then permanently persist within genomic DNA (168). The biological relevance of rNMP incorporation in genomic DNA is emerging from a growing body of recent scientific studies. Whatever the cause of the $\mathrm{rNMP}(\mathrm{s})$ incorporation, the additional 2'-OH group on one or more $\mathrm{rNMP}(\mathrm{s})$ alters DNA elasticity and structure in a sequence-dependent manner, destabilising the DNA backbone, increasing the susceptibility to DNA hydrolysis, and finally causing strand cleavage and/or mutability $(148,169-174)$. The genomic DNA stability, perturbed by the $\mathrm{rNMP}(\mathrm{s})$ presence, is preserved by the combined action of several enzymes orchestrated in a unique pathway called ribonucleotide excision repair (RER) (160). One of the most important RER enzymes is RNase H2 (175), an endonuclease involved in the cleavage of the phosphodiester bond at the $5^{\prime}$ side of a single, or more allocated in series, rNMP(s) embedded in DNA. Similar to BER, FEN1 incises the 3' side of the partially excised rNMP to definitely release it from the genomic DNA, leaving a nick that will be finally repaired by Pol $\delta$, Pol $\varepsilon$ and Lig I enzymes $(175,176)$. The missing processing of rNMPs embedded in DNA results in embryonic lethality in mice $(160,177)$, as a consequence of activation of a p53-dependent damage response (178), cell cycle arrest and blockage of DNA replication $(179,180)$. Moreover, it has been documented how mutations in each of the three RNase H2 subunits are correlated with the onset of the Aicardi Goutières syndrome (AGS), an inflammatory disorder $(181,182)$ whose effects are mainly associated with increased levels of $\mathrm{rNMP}(\mathrm{s})$ incorporated in genomic DNA, that partially stimulates the activation of the innate immune response by IFN $\gamma$ signaling and DDR $(160,180,183,184)$. Notably, a recent work performed on mice, expressing different types of AGS-mutated RNase H2, has demonstrated the existence of a threshold in rNMPs levels during embryonic development. When the level is moderate, an activation of the cGASSting DNA sensing innate immune response leading to perinatal lethality was observed. When a high abundance of rNMPs exceeded the threshold, the subsequent activation of p53-dependent DNA 
damage caused early embryonic lethality (185). Importantly, a relationship between RNase $\mathrm{H} 2$ and rNMPs incorporation with cancer is emerging. Screening of a cohort of patients with gastric cancers has recently revealed an association between the onset of gastric cancer and mutations in gene coding for the subunit B of RNase $\mathrm{H} 2$ (186). In parallel, a recent study has shown that RNase H2 can be also considered as a colorectal tumour suppressor gene (187). Furthermore, loss of RNase H2, in the murine epidermis, results in spontaneous DNA damage and development of squamous cell carcinoma (188). In light of this, it becomes clear how additional investigations are needed for clarifying the association between mutated RNase $\mathrm{H} 2$ and/or rNMP(s) DNA-incorporated and pathology. Although the deleterious effects of $\mathrm{rNMP}(\mathrm{s})$ incorporations in DNA are well-known, a new hypothesis has been suggested involving a putative helpful role for rNMP(s). Specifically, it has been shown that more rNMPs, consecutively incorporated in yeast genomic DNA, may mark the nascent DNA strand, initiating programmed mating-type switching (189). Furthermore, a recent study reported how the erroneous ability of polymerase $\mu$ ( $\mathrm{Pol} \mu$ ) to discriminate rNMPs during the NHEJ pathway (190-192) could be detrimental, as well as advantageous, for the cell. Indeed, by inserting rNMPs with a higher base fidelity compared with dNMPs (192), Pol $\mu$ might stimulate Lig IV in promoting initiation of the NHEJ mechanism (193). In parallel, another interesting observation has linked the activity of RNase $\mathrm{H} 2$ with the mis-match repair (MMR) pathway $(164,194)$. The rNMP cleavage mediated by RNase H2 works as a signal for MMR enzymes, which are then stimulated to process the mismatched sites located in the surroundings. Finally, although the results show that rNMP in DNA induced a decrease of DNA polymerases processivity (195), the choice of which rNMP is embedded in the template strand can influence the DNA synthesis (195-197). A still unanswered question is whether alternative DNA repair systems, other than the RER pathway, may remove rNMPs embedded in DNA $(147,198,199)$. Until now, topoisomerase I (Top1) is the only enzyme able to cleave rNMPs embedded in DNA, when the RER pathway is not working. Top1 is an essential enzyme thought to resolve DNA supercoils generated during replication and transcription $(200,201)$. It has been shown that Top1, cleaving at the $5^{\prime}$-side of rNMPs $(199,202)$ and generating $5^{\prime}-\mathrm{OH}$ and $3^{\prime}$-cyclic $2^{\prime}-3^{\prime}$ phosphate as DNA termini, is able to compensate for RNase H2 deficiency, although it causes high levels of DNA mutations $(199,203)$. Later, the cleavage is followed by nick processing by Srs2-Exo1 $(204,205)$. A recent analysis of yeast has identified a role of Apn2 (homologous to human APE1) in restoring the genome integrity perturbed by the Top1-catalysed rNMPs cleavage by resolving 3 '-end blocks generated by Top1 (206). Recently, Zimmermann et al. (207) have shown how the cleavage of rNMPs by Top1 results in the formation of PARP-trapping lesions that impede DNA replication. In contrast, studies performed on the MMR and the nucleotide excision repair (NER) pathways have shown the inefficiency of these pathways in the processing of this particular lesion $(199,208)$. The NER pathway generally excises bulky and non-bulky DNA base adducts (209). Because rNMP incorporation distorts the DNA backbone, NER enzymes could be good candidates in repairing this type of damage. Data obtained from Bacteria showed an involvement of NER factors in the removal of rNMPs in the DNA $(210,211)$, in contrast to what is observed for human NER factors, which are not involved in rNMP repair (208). Evidence about this difference has not improved, but may suggest that NER factors might have lost this function during evolution. In contrast, data collected in vitro have shown that the MMR mechanism can target mismatches with
rNMPs both in Escherichia coli and Saccharomyces cerevisiae genomic DNA (197). Increasing knowledge in this field represents an important goal in the DNA repair and in the pathogenesis associated with this type of damage. For this reason, we improved the study of DNA repair mechanisms acting on rNMPs embedded in DNA, under conditions in which RER is functionally inactive. In our laboratory, while studying a putative role of BER in the removal of rNMPs embedded in the DNA, we discovered that BER was not active on this type of lesion (7). In this context, several published reports have hypothesised that, among the many millions of rNMPs that are introduced into the mammalian genome per cell cycle (198), damaged rNMPs (such as the ribose monophosphate abasic site and oxidation) can also be incorporated into DNA. In fact, RNA molecules, as well as rNMPs present in the nucleotide pool, are also susceptible to oxidative insults $(108,212)$. Although not fully explored, the generation of hydroxyl radicals from oxidative stress could be the cause of the conversion of the deoxyribose sugar into ribose in vitro and in vivo (212). This can happen both in the cellular nucleotide pool and directly into the DNA. Additional data are needed to support this hypothesis. Moreover, a significant generation of abasic sites has been demonstrated upon RNA oxidation and alkylation (23). For these reasons, whereas the role of the RNase $\mathrm{H} 2$-initiated RER mechanism of DNA repair in recognising and cleaving rNMPs embedded in DNA is well-established $(178,198)$, little is known regarding the possible involvement of the RER pathway, or other DNA repair pathways, in the removal of damaged rNMPs. Again, a role of the BER pathway was addressed in our laboratory. For its abilities, BER may represent one of the best candidates to work on modified rNMP(s) during DNA repair. Although APE1, in contrast to RNase H2, does not work on rGMP embedded in DNA (7), it has nevertheless been demonstrated to cleave the ribose monophosphate abasic site incorporated in the DNA (Figure 1). In contrast with expectations, RNase $\mathrm{H} 2$ does not work on this damaged base, confirming an APE1-exclusive function. Additionally, we focused on the 8-oxo-guanosine (8-oxo-G)-modified base. First, we found an inability of human RNase $\mathrm{H} 2$ in recognising and cleaving this modified rNMP embedded in DNA. We then studied the BER pathway, in which one of the most known bifunctional glycosylases, active in processing the 8-oxo-dG and FapyG DNA lesions, is OGG1 $(213,214)$. Although OGG1 also interacts with undamaged G, it is specific enough to discriminate and not to process it (215). In our recent report (7), we found that OGG1 was able to recognise and bind the 8-oxo-G embedded in DNA, as efficiently as its canonical substrate (8-oxo-dG) (Figure 1). Moreover, when co-incubated with APE1, it showed no glycosylase activity, being unable to process the 8-oxo-G and to generate a substrate suitable for APE1. Notably, we discovered and characterised the NIR activity of APE1 on the 8-oxo-G substrate. APE1, although weakly, was able to cleave 8-oxo-G using experimental conditions specific for NIR. Furthermore, as observed during canonical NIR activity, APE1 works as an 3'-exonuclease on the newly generated $3^{\prime}-\mathrm{OH}$ terminus (Figure 1). We recently improved our knowledge in this topic by discovering that, although human and Archeal RNase H2/II proteins are not able to process the 8 -oxo-G or the ribose monophosphate abasic sites embedded in DNA, they were able to bind these damaged bases. In contrast, we found that E.coli RNase HII possessed a high enzymatic activity on both the 8-oxo-G and ribose monophosphate abasic containing substrates, suggesting a loss of function during phylogenetic evolution (216). Recently, it has been found that $\mathrm{rNMP}(\mathrm{s})$ is also incorporated by DNA polymerase $\gamma$ in mitochondrial DNA (mtDNA), in heavy as well as light strand DNA. 
Increased levels of embedded ribonucleotides, affecting mtDNA stability and impairing new rounds of mtDNA replication, may contribute to new pathogenic mechanisms (217-220). A recent work conducted on yeast has demonstrated that a repair mechanism for rNMPs mis-incorporated is lacking (221). Further studies are needed regarding the consequences of rNMP incorporation in mtDNA and its repair processing.

\section{BER enzyme signatures in cancer}

Because of the involvement of the BER pathway in cancer and because of evidence regarding BER factor secretion (see paragraph below), extensive efforts have been directed to evaluate the prognostic and predictive tumour biomarker potential of BER enzymes (222) (Figure 2). Several studies described the alterations of the APE1 genetic sequence, expression and distribution in several tumours (223). In different types of solid tumours, an increased APE1 expression is associated with lower survival rates and, at the same time, an aberrant nuclear and cytoplasmic localisation of APE1 is a sign of poor outcome (224). A study performed on a cohort of patients with gallbladder cancer showed that high expression of APE1 protein was positively correlated with tumour stage and positive lymph node status; in contrast, no association with tumour differentiation and metastatic condition was detected (225). It should be noted that not only the protein level, but also the subcellular localisation of APE1 was altered. APE1 displayed a nucleo-cytoplasmic localisation, especially in patients in which a higher level of protein was detected (225). Regarding hepatocellular carcinoma (HCC), an upregulation of APE1 occurred at the transcriptional level, which was linked with the progression of the disease (226). Moreover, further studies showed an enhanced APE1 protein expression in tumour tissue compared with healthy controls (227). Immunostaining analysis revealed elevated levels of APE1 in pancreatic adenocarcinoma tissue (228), and also in prostate, esophageal, gastric, salivary gland carcinomas (229-232) and non-small-cell lung cancers (233). In all cases, this feature correlated with a lower survival of patients (231233). Furthermore, in tumour tissues derived from ovarian cancer, several studies highlighted an altered overexpression and localisation of APE1 (234,235). However, in different cohorts of ovarian cancer, there were conflicting studies regarding the correlation between the subcellular localisation of APE1 and cancer outcomes (223). In colorectal cancer (CRC), increased APE1 levels and cytoplasmic localisation in tumour tissue and colon cancer stem cells have been observed $(236,237)$; furthermore, the APE1 overexpression

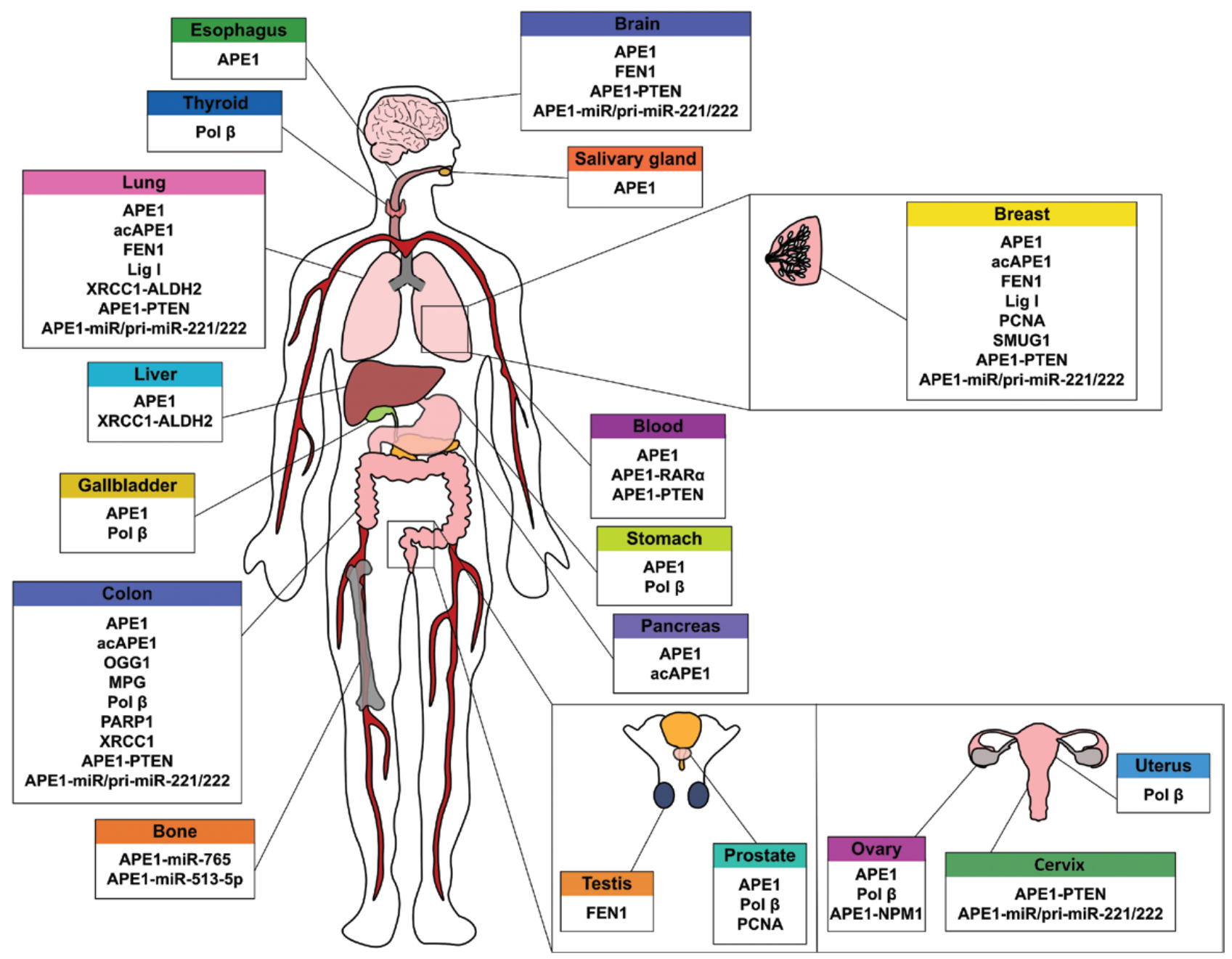

Figure 2. Overview of the most common BER-related alterations and relevance as potential molecular biomarkers in cancer. Symbolic illustrations of organs are shown, in which the main alterations of BER enzymes or BER-related alterations are listed into the connected colored boxes. See the text for further information. Figure available in colour online. 
in liver metastasis has been correlated with poor prognoses (238). Concerning breast cancer, conflicting data are available. Some analyses reported that APE1 expression was higher in patients with triple negative breast cancer (TNBC), which was associated with tumour size (239), while another study reported that a decreased APE1 level was linked to aggressive histological features and triple negative phenotypes (240). Similarly, loss of APE1 expression and poor prognoses were found in glioma compared with normal brain tissue (241); however, an increase in the APE1 protein was observed in post-treatment glioblastoma tumours (242). Along with the expression level of APE1, its acetylated status has also been considered because it modulates APE1 activity. In particular, elevated levels of acAPE1 in colon, lung and pancreatic cancer tissues, leading to an increased AP-endonuclease activity, have suggested the occurrence of a compensatory mechanism in response to genotoxic stress induced by chemotherapy to maintain tumour cell proliferation capacity (243). Decreased APE1 acetylation status was associated with TNBC (244), demonstrating how PTMs occurring on APE1 is related to cancer development (244). Finally, a transcriptome analysis revealed an increased expression of APE1 and other genes of its interactome in the lymphocyte $\mathrm{T}$ cells of childhood acute lymphoblastic leukemia (245). Notably, correlation analyses were performed to link the overexpression of APE1 and the levels of its interacting proteins. For example, a cytoplasmic overexpression of APE1 and of its interacting protein, NPM1, were found in different studies, such as in a cohort of patients with ovarian cancer (246) with serous ovarian adenocarcinomas (247), indicating an association with lymph node metastasis, chemoresistance and an overall poor prognosis. Another positive correlation was observed between retinoic acid nuclear receptor $(\mathrm{RAR} \alpha)$ and APE1 in patients with multiple myeloma (248). Indeed, the binding of RAR $\alpha$ to its DNA response elements (RARE) is dependent on the redox function of APE1 (249). However, an inverse association has been found between APE1 and the tumour suppressor, PTEN, in glioblastoma, colorectal, breast, cervical and non-small cell lung cancers (6). Notably, high levels of PTEN and low levels of APE1 mRNA expression were associated with better prognoses in human melanomas (250). Furthermore, not only proteins but also miRNAs have been shown to be correlated with APE1 in tumours. Indeed, a negative correlation was found between miR765 and APE1 expression in osteosarcoma patients. Specifically, a higher expression of miR-765 was associated with decreased APE1 and good survival in response to cisplatin treatment (251). In addition, the downregulation of miR-513-5p was found in patients with osteosarcoma. The decreased level of miR-513-5p has been correlated with APE1 overexpression and radioresistance (252). Finally, an inverse correlation between APE1 and miR/priR-miR-221/222 expression was found in a cohort of human cancer specimens, such as glioblastoma, colorectal, breast, cervical and non-small cell lung cancers (6). In this context, the possibility to create a screening panel of the biomarker interactomes, involved in tumour development, should be carefully evaluated.

The expressions of other BER enzymes have been evaluated in the literature as potential biomarkers. For instance, OGG1 is estimated to be a prognostic biomarker of CRC patients survival; and low levels of OGG1 mRNA in marginal colon tissue were associated with longer survival in CRC patients following therapeutic surgery (253). Furthermore, low mRNA and protein levels of SMUG1 were associated with adverse clinic-pathological features in breast cancer patients (254). Regarding CRC, an overexpression of $N$-methylpurine DNA glycosylase (MPG), OGG1, APE1, Pol $\beta$, PARP1 and XRCC1 was also shown to be linked with poor pathological outcomes
(222,255); only the overexpression of MPG and Pol $\beta$, and not of XRCC1, were positively correlated with higher rates of tumour proliferation when each individual CRC case was taken into account (222). Moreover, an increased expression of Pol $\beta$ was also observed in gastric, uterine, prostate, ovarian and thyroid carcinomas (256). Limited to Pol $\beta$, overexpression was also consistently associated with tumour stage of gallbladder cancer (225). Furthermore, a cancer-related isoform of PCNA has been specifically detected in prostate and breast cancer $(257,258)$. Moreover, a positive correlation between the upregulation of FEN1 and aggressiveness in breast cancer patients has been observed (259). FEN1 has been also found overexpressed in testis, lung and brain tumours (260). In the case of XRCC1, its overexpression, in lung and liver-cancer patients, was associated with low expression of aldehyde dehydrogenase 2 (ALDH2), resulting in a poor prognostic value, suggesting that an efficient DNA repair mechanism is required in the presence of high aldehyde metabolism (261). Finally, an increased expression of Lig I has been reported in breast and lung tumour tissues (262).

Very importantly, along with the levels of the proteins, it is also fundamental to evaluate their activity, as biomarkers. The possibility to measure the DNA repair capacity (DRC) could provide a method to predict the outcome of a particular disease. For instance, 5 -fluorouracil (5-FU) is the main chemotherapeutic drug used against solid tumours. The BER pathway is involved in the DNA repair process in response to 5-FU lesions, thus, removing 5-FU and uracil metabolites from the DNA (263). A prospective study demonstrated the association between DRC of BER in response to 5-FU and patient survival in a cohort affected by CRC. In the study, the overall survival was correlated with high activity of BER in non-malignant adjacent mucosa and low BER in tumour tissue in patients with TNM Stages II and III, together with good therapy response (264). Interestingly, APE1 enzymatic activity was also higher in gallbladder tumour patients than in chronic cholecystitis patients (225). Taking into account these results, Chaim et al. (265) developed a fluorescentbased multiplex flow-cytometric host cell reactivation assay, based on the transfection of reporter plasmids in primary $\mathrm{T}$ lymphocytes, that allowed measurement of the activity of BER enzymes, such as different glycosylases (OGG1, MPG, MUTYH and UNG) and APE1. The possibility to measure the activity of OGG1 and MPG through a DNA glycosylase-mediated cleavage of molecular beacons was demonstrated by Hu et al. (266).

\section{BER polymorphisms and cancer}

The identification of single-nucleotide polymorphisms (SNPs) in DNA repair genes has become increasingly important since they can determine a different DNA repair capacity and consequently generate higher frequency of mutations (267). Therefore, SNPs can be associated with a high susceptibility to cancer and with chemotherapy and radiotherapy resistance (268). Different SNPs involved in carcinogenesis have been identified in the main DNA repair pathways, such as BER, NER, MMR and double-strand breaks repair (DSBR) $(267,269,270)$. For all these reasons, DNA repair pathway polymorphisms are of interest as predictive factors in the clinic. Here, we report the most frequent functional polymorphisms that have recently been published concerning the BER pathway enzymes (see Wallace et al. (14) for the complete list of polymorphisms).

Several evidences have been reported regarding the main BER DNA glycosylases, such as OGG1, NEIL3 and mutY DNA glycosylase (MUTYH). Several studies have been reported regarding the most studied OGG1 polymorphic variant: Ser326Cys (rs1052133). Up to 
now, data regarding OGG1 Ser326Cys polymorphism and cancer has been conflicting, probably due to the susceptibly of the different populations and the different types of tumours that have been studied. Earlier evidence suggested that OGG1 Ser326Cys polymorphism did not increase the risk of developing lung cancer (271). Nevertheless, conflicting data of OGG1 Ser326Cys polymorphism was present for CRC $(272,273)$ and breast cancer $(274,275)$. However, a more recent study has shown how OGG1 Ser326Cys heterozygous genotype (Ser/Cys) is associated with a decrease of bladder cancer risk in a cohort of a Belarusian population (276). In a follow-up study, the same research group demonstrated how this polymorphism could affect cancer-related genes and the methylation status in patients diagnosed with bladder cancer. Indeed, the frequency of the oncogenic phosphatidylinositol 3-kinase (PIK3CA) mutations was reduced in smokers of heterozygous genotype (Ser/Cys) and minor allele (Cys) carriers. On the contrary, the same polymorphism correlated with an increased frequency of mutations in the RAS loci and affected the levels of runt-related transcription factor 3 (RUNX3) and ISL LIM homeobox 1 (ISL1) methylation (277). In addition, it has been shown that OGG1 Ser326Cys homozygous genotype (Cys/Cys) represents a risk factor for childhood leukaemia (278). An explanation is that the Cys/Cys genotype is associated with lower OGG1 activity, which translates to an increased AML relapse (279). Concerning polymorphisms involving other glycosylases, NEIL3 Pro117Arg (rs7689099) has been suggested for its relevance in susceptibility, survival and therapy outcome in patients with CRC from the Czech Republic and Austrian cohorts (280). Finally, MUTYH polymorphism Gln324His (rs3219489) (Gln/His and His/His) was associated with increased CRC risk in a Polish population (281) and Gln324His (His/His) was linked to an higher lung cancer risk in a Japanese population (271).

Concerning the endonuclease APE1, the most frequent polymorphism is Asp148Glu (rs3136820), covering about $46 \%$ of the population (14). Again, conflicting data are present in the literature regarding bladder, breast, colorectal and lung cancer $(14,270)$. Furthermore, a recent meta-analysis has not shown any association between the Asp148Glu polymorphism and prostate cancer; however, in the same study, when a hospital-based population was considered, the presence of Asp148Glu dominant variants (Glu/ Glu and Asp/Glu) was proposed as a risk factor to develop prostate cancer (282). In addition, in a recent study, APE1 Asp148Glu was not considered as a risk factor for HCC in an Egyptian population (283). These discrepancies probably are attributable to the fact that the Asp148Glu variant exhibits normal endonuclease activity (284). However, increasing incidence of AP sites has been observed in leukocytes derived from breast cancer patients compared to controls, thus increasing the risk of cancer (285). Finally, a meta-analysis has suggested that the APE1 polymorphism rs1760944 T > G could have a protective role in cancer development among Asians (286).

Few data are available regarding the association between PARP1, Pol $\beta$, FEN1 polymorphisms and tumours. Liu et al. (270) have reported the latest data regarding these BER enzyme polymorphisms and the risk of CRC.

Different studies concerning XRCC1 polymorphisms and the susceptibility to cancer have been reported. In a Caucasian population, the risk of gliomas was associated with both the homozygous variants of XRCC1 Gln399Gln and XRCC3 Met241Met (287). Another variant of XRCC1, Arg194Trp, was shown to be a risk factor for CRC in a Chinese and Kashmiri population with heterozygous (Arg/ $\operatorname{Trp})$ and homozygous variants $(\operatorname{Trp} / \operatorname{Trp})(288,289)$. The same polymorphism was considered a susceptibility factor for HCV-related hepatocellular carcinoma progression in an Egyptian population; however, no association was found when Arg280His or Arg399Gln genotypes were taken into account (283). In a Chinese cohort, the polymorphism located at the promoter of XRCC1 (XRCC1 rs3213245 C genotype) was associated with a decreased risk of cervical cancer, due to a transcriptional overexpression of XRCC1, as a consequence of the enhanced binding of the Sp1-Knox-20 complex to the promoter region. Moreover, a decreased expression of XRCC1 has been observed in carriers of the XRCC1 rs3213245 T genotype, increasing the risk of cancer (290). BER polymorphism can affect the methylation status of some tumour suppressor genes, as previously mentioned. For instance, focusing on XRCC1, in a study which considered a cohort of patients with bladder cancer, the XRCC1 Arg399Gln (rs25487) heterozygous (Arg/Gln) genotype increased the frequency of p16 and TIMP3 methylation (277).

\section{Extracellular secretion of BER proteins: novel insights in cancer biology}

It has been widely reported how, in cancer cells, the activation of the BER pathway, in response to the chemotherapy treatment, promotes a resistant phenotype (291). Through the activation of repair mechanisms, in fact, stressed cancer cells can escape from cell death and maintain their ability to grow (292). This is the reason why BER enzymes are considered a good target for developing novel anti-cancer therapies. The chemoresistance phenomenon is not only connected with the activation of repair pathways in cancer cells, but also with the multifunctional role of the BER enzymes, particularly associated with the regulation of gene expression $(133,293)$. Another interesting aspect supporting the chemoresistance occurrence is the capability of drug treatments to induce a modulation of the immune responses (294). Some secreted factors are also responsible for the modulation of immune responses, acting in the extracellular tumour microenvironment, to affect the metabolism of the accepting cancer cells (293). This property suggests a new scenario regarding the dynamic molecular mechanisms that are activated by the secreted factors that influence the behavior of the surrounding cancer cells. Specifically, it would be interesting to study some BER or BERrelated proteins regarding their possible roles as damage associated molecular patterns (DAMP) proteins in tumour progression, such as the secreted protein high mobility group box 1 (HMGB1) (Figure 1). HMGB1 is a nuclear DNA repair protein that acts as a chromatin remodeling factor and as a transcriptional regulator, but it is also an extracellular protein, that can act as a chemokine and cytokine, having a role in cell signaling and inflammation $(295,296)$. As a DNA repair protein, its accumulation is concomitant with oxidative DNA damage and, for this reason, it has been defined as an early DDR factor (297). It is also considered as a BER co-factor, because it is able to affect the activities of BER enzymes. HMGB1 stimulates APE1 endonuclease activity on AP sites, and promotes long-patch BER, through the stimulation of FEN1 flap cleavage activity (295). It is known that oxidative stress is responsible for HMGB1 translocation, release and activity (298). These secreted proteins therefore have a pro-inflammatory role (299). Indeed, HMGB1 secretion is induced upon chemotherapeutic treatment, and due to its capability to stimulate the chemokine CXCL11, it contributes to the antitumour immune response $(294,300)$. In contrast, current data elucidate how this secreted protein is also connected to cancer development, due to its role in the progression of esophageal squamous cell carcinoma (ESCC) (293). These data suggest the importance of activated paracrine signaling in the tumour microenvironment for cancer evolution 
and progression. Interestingly, other proteins whose role was initially thought to be restricted only to the nuclear compartment and with the maintenance of DNA structure and with the regulation of gene expression, have been recently demonstrated to play a role in paracrine signaling. Even if these proteins lack the leader sequence that promotes the canonical secretion through the endoplasmic reticulum and Golgi apparatus (301), their secretion is clearly documented. As secreted factors, the function of these proteins seems to be related to cytokines activity. One example is YB-1, an additional APE1-interacting protein, whose role as an extracellular mitogen was described in mesangial and monocyte cells after inflammatory challenges (302) (Figure 1). There are also consistent data about the secretion of the APE1 enzyme, whose elevated intracellular protein levels in cancer are linked to poor prognosis (141). APE1 confers resistance to chemotherapy or radiotherapy treatments in different kind of tumours like gliomas, breast cancer, HCC, thyroid cancer and osteosarcoma (226,303-305). Recent findings concerning APE1 cytoplasmic relocation and poor prognostic correlation in HCC cells led to new investigations about the multiple functions of this BER enzyme and to its emergent role in cancer progression relative to its own localisation $(141,226)$. Studies regarding its possible secretion were reported since 2004, when it was predicted that APE1 was also a non-classically secreted protein (306). Its extracellular secretion was later revealed in the plasma of endotoxemic rats (307), and in the same year, the regulation of APE1 secretion occurring through PTMs and inducing its extracellular release was characterised. It seems, in fact, that the acetylation of residues K6/K7 in the APE1 $\mathrm{N}$-terminal region promotes its secretion (308). APE1 acetylation as a post-translational modification promoting its extracellular release, was also verified in TNBC, in which APE1 secretion and its action as an autocrine and paracrine factor seems to promote the apoptosis of cancer cells (309). Reports regarding APE1 functions as a secreted protein were also observed in monocytes, where an APE1 extracellular role under inflammatory conditions and its capability to promote the production and secretion of IL-6 were proven (310). We recently demonstrated a role of extracellular APE1 in HCC (311), finding a positive correlation between serum and tissue APE1 amounts in the HCC cohort analysed. These data prompted us to consider serum APE1 as a new diagnostic biomarker in HCC. We also showed that the exogenous APE1 protein was able to induce IL-6 and IL-8 expression in the JHH-6 HCC cell line, suggesting its role as a paracrine pro-inflammatory factor. Hence, these findings suggested that exogenous APE1 was able to modulate the inflammatory status of the tumour microenvironment, showing its possible role in cellular senescence and in tumour invasiveness (310-312). We believe that further characterisation of the roles of secreted BER proteins is required for an understanding of their role in tumour biology.

\section{Cancer organoids as a novel approach to translate BER proteins in personalised medicine}

Human cell lines and in vivo animal models have been largely used to characterise the biochemical functions and the biological relevance of BER proteins, and are a well-known model in cancer translational research. However, a better knowledge of the adult stem cells in combination with three-dimensional (3D) cultures has allowed the establishment of organoids as an advanced model

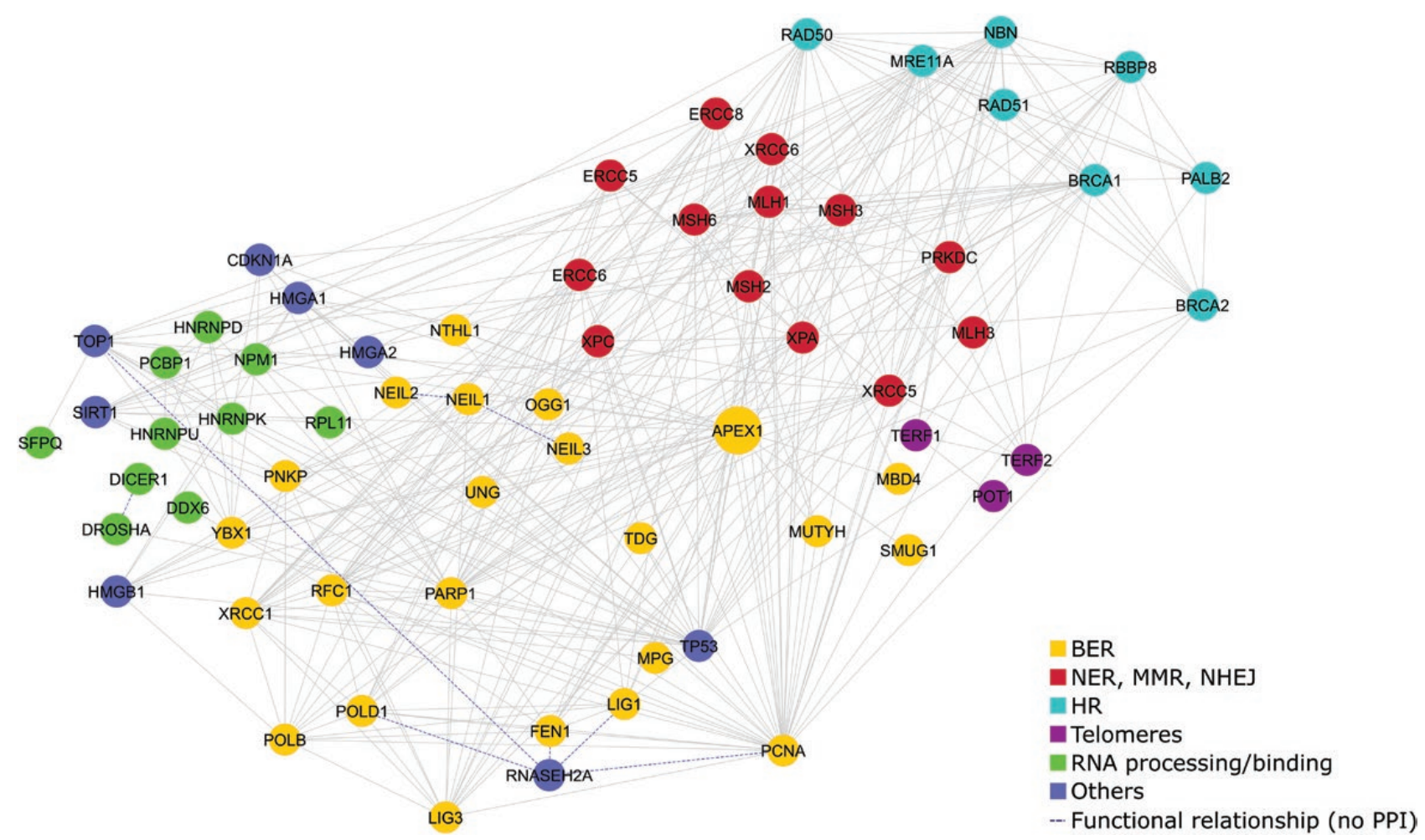

Figure 3. Protein-protein interaction network of proteins involved in DNA repair/stability and in RNA processing. Data, obtained from the InWeb_InBioMap platform (no network expansion, confidence score cut-off $=0.156$ [recommended value]; (322)), shows the direct (solid lines) and indirect (dashed lines) interactions existing between BER (yellow nodes), nucleotide excision repair/DNA mismatch repair/non-homologous end joining (NER, MMR, NHEJ, red nodes), homologous recombination (HR, cyan nodes), telomeres (purple nodes) and RNA processing/binding (green nodes) proteins, as well as a few others (blue nodes) with heterogeneous molecular functions. Figure available in colour online. 
system $(313,314)$. Organoids consist of a novel 3D technology, which allows the establishment of long-term stem cell-based cultures. Organoids represent a valuable tool to study the biology of stem cells and to evaluate their contribution to tissue homeostasis. Organoids have numerous valuable applications and may be used to improve our knowledge about several disease pathways $(315,316)$, especially in cancer biology. Due to the intriguing mechanisms characterising tumour aetiology, different studies have focused on personalised precision treatments for cancer. By using patient-derived tumour organoids (PDOs), studies have tried to understand and reproduce the disease complexity and heterogeneity, for developing patient-specific therapies (317), because organoids reflect the key-features of the original patient's tissue (316). Different types of analyses involving normal and tumour PDOs have been performed, such as genome, transcriptome (318) and proteome analyses (317), but DNA repair mechanisms have not been extensively studied. Based on previous studies, normal organoids could be engineered to study DNA repair enzymes deficiencies and evaluate mutational signatures in cancer. To date, few studies regarding BER enzymes and PDOs have been published. In a recent study, human normal intestinal organoids were engineered with the CRISPR-Cas9 genome editing system to delete key DNA repair genes, such as the MMR gene MLH1 and the BER gene NTHL1 (319). This approach proved that MLH1 knockout organoids reflected mismatch repair-deficiency found in CRC; moreover, the lack of NTHL1 was a predisposition to the development of a range of cancers, such as colorectal and breast cancer (319). Furthermore, the opportunity to perform drug-screening assays on PDOs is very appealing, considering that chemoresistance can occur in patients (320). Indeed, we recently tested the APE1 endonuclease inhibitor (Compound \#3) on CRC PDOs, carrying a wild-type, and a stop-gain or missense mutant TP53, highlighting that the effectiveness of the inhibitor was dependent on the presence of wild-type or gained-of-function mutant p53 and independent of the null-mutant p53 (321). Therefore, we strongly believe that the use of these 3D-cell models should be carefully considered in translating BER biochemistry into personalised medicine.

\section{Conclusions}

Forty years after the first characterisation of the BER glycosylases, integration of this pathway (Figure 3, yellow nodes) within the DDR (Figure 3, red and cyan nodes) has been somewhat elucidated. The recent discovery of a functional role of this highly conserved pathway in genomic stability, gene expression regulation and RNA processing/decay (Figure 3, purple, blue and green nodes) lays the foundations for the starting point of a new challenging field of research. These achievements will significantly contribute to our understanding of the complexity of BER and the DDR, in general. Moreover, these findings will help add further elements to the comprehension of the role of BER in human physiology and pathology, possibly opening new unpredicted therapeutic perspectives. Many issues still remain to be addressed and are prompting researchers to continue their efforts to understand the crosstalk between DNA damage and gene expression regulation. This can be considered as a fundamental process responsible for the adaptive cellular mechanisms to genotoxic damage, and is a concern regarding several possible mechanisms of cancer chemoresistance.

In the last 40 years, we have learned much regarding BER biochemistry and biology. However, a number of questions still remain to be elucidated.
- Should we reinterpret the overall biological function of DDR and its role in cancer based on the data about the relevance of the non-canonical functions of DDR and BER proteins?

- Several BER and other DDR enzymes are catalytically active on different modified RNA substrates. Should we ascribe to them an important role in RNA decay or in the editing mechanisms?

- Might the unique ability of BER DNA glycosylases to recognise even subtle chemical modifications of nucleobases serve to distinguish between normal and aberrant RNA molecules?

- Is there a concerted action between DNA glycosylases, APE1 and the downstream enzymes involved in decay/repair of damaged RNA molecules?

- Can the effects of BER enzymes, both on mRNA and ncRNA, alter the protein translational machinery, thus, contributing to chemoresistance through post-transcriptional regulation of gene expression?

- Is the role of some DNA repair proteins in secreted exosomal particles due to their canonical or non-canonical functions?

In 2009 , thanks to the use of unbiased proteomics and genomics strategies, we were able to propose the novel concept of noncanonical functions of APE1 in RNA metabolism. We strongly believe that an integrated view of the canonical roles of BER proteins in DNA repair and in RNA functions will lead to new important and unexpected discoveries in the future.

\section{Funding}

This work was supported by grants from the Associazione Italiana per la Ricerca sul Cancro (IG14038) and the European Union, European Regional Development Fund and Interreg V-A Italia-Austria 2014-2020 ITAT1096-P (Program PRECANMED ITAT1009 CUP G22F16000890006) to G.T.

\section{Acknowledgements}

The authors thank all the members of the GT lab for constructive feedback during the development of this work.

Conflict of interest statement: None declared.

\section{References}

1. Hein, N., Hannan, K. M., George, A. J., Sanij, E. and Hannan, R. D. (2013) The nucleolus: an emerging target for cancer therapy. Trends Mol. Med., 19, 643-654.

2. Hanahan, D. and Weinberg, R. A. (2011) Hallmarks of cancer: the next generation. Cell, 144, 646-674.

3. Wickramasinghe, V. O. and Venkitaraman, A. R. (2016) RNA processing and genome stability: cause and consequence. Mol. Cell, 61, 496-505.

4. Michelini, F., Jalihal, A. P., Francia, S., et al. (2018) From "cellular" RNA to "smart" RNA: multiple roles of RNA in genome stability and beyond. Chem. Rev., 118, 4365-4403.

5. Antoniali, G., Lirussi, L., Poletto, M. and Tell, G. (2014) Emerging roles of the nucleolus in regulating the DNA damage response: the noncanonical DNA repair enzyme APE1/Ref-1 as a paradigmatical example. Antioxid. Redox Signal., 20, 621-639.

6. Antoniali, G., Serra, F., Lirussi, L., et al. (2017) Mammalian APE1 controls miRNA processing and its interactome is linked to cancer RNA metabolism. Nat. Commun., 8, 797.

7. Malfatti, M. C., Balachander, S., Antoniali, G., et al. (2017) Abasic and oxidized ribonucleotides embedded in DNA are processed by human APE1 and not by RNase H2. Nucleic Acids Res., 45, 11193-11212.

8. Dianov, G. L., Souza-Pinto, N., Nyaga, S. G., Thybo, T., Stevnsner, T. and Bohr, V. A. (2001) Base excision repair in nuclear and mitochondrial DNA. Prog. Nucleic Acid Res. Mol. Biol., 68, 285-297. 
9. Krokan, H. E. and Bjørås, M. (2013) Base excision repair. Cold Spring Harb. Perspect. Biol., 5, a012583.

10. Markkanen, E. (2017) Not breathing is not an option: how to deal with oxidative DNA damage. DNA Repair (Amst)., 59, 82-105.

11. Sidorenko, V. S., Nevinsky, G. A. and Zharkov, D. O. (2007) Mechanism of interaction between human 8-oxoguanine-DNA glycosylase and AP endonuclease. DNA Repair (Amst)., 6, 317-328.

12. Sidorenko, V. S. and Zharkov, D. O. (2008) Role of base excision repair DNA glycosylases in hereditary and infectious human diseases. Mol. Biol., 42,794-805.

13. Takao, M., Zhang, Q. M., Yonei, S. and Yasui, A. (1999) Differential subcellular localization of human MutY homolog (hMYH) and the functional activity of adenine:8-oxoguanine DNA glycosylase. Nucleic Acids Res., 27, 3638-3644.

14. Wallace, S. S., Murphy, D. L. and Sweasy, J. B. (2012) Base excision repair and cancer. Cancer Lett., 327, 73-89.

15. Svilar, D., Goellner, E. M., Almeida, K. H. and Sobol, R. W. (2011) Base excision repair and lesion-dependent subpathways for repair of oxidative DNA damage. Antioxid. Redox Signal., 14, 2491-2507.

16. Hill, J. W., Hazra, T. K., Izumi, T. and Mitra, S. (2001) Stimulation of human 8-oxoguanine-DNA glycosylase by AP-endonuclease: potential coordination of the initial steps in base excision repair. Nucleic Acids Res., $29,430-438$.

17. Prakash, A., Doublié, S. and Wallace, S. S. (2012) The Fpg/Nei family of DNA glycosylases: substrates, structures, and search for damage. Prog. Mol. Biol. Transl. Sci., 110, 71-91.

18. Bailly, V. and Verly, W. G. (1988) Possible roles of beta-elimination and delta-elimination reactions in the repair of DNA containing AP (apurinic/ apyrimidinic) sites in mammalian cells. Biochem. J., 253, 553-559.

19. Iyama, T. and Wilson, D. M., III. (2013) DNA repair mechanisms in dividing and non-dividing cells. DNA Repair (Amst)., 12, 620-636.

20. Bauer, N. C., Corbett, A. H. and Doetsch, P. W. (2015) The current state of eukaryotic DNA base damage and repair. Nucleic Acids Res., 43, 1008310101.

21. Dianov, G. L. and Hübscher, U. (2013) Mammalian base excision repair: the forgotten archangel. Nucleic Acids Res., 41, 3483-3490.

22. Lindahl, T. (1993) Instability and decay of the primary structure of DNA. Nature, 362, 709-715.

23. Loeb, L. A. and Preston, B. D. (1986) Mutagenesis by apurinic/apyrimidinic sites. Annu. Rev. Genet., 20, 201-230.

24. Demple, B., Herman, T. and Chen, D. S. (1991) Cloning and expression of APE, the cDNA encoding the major human apurinic endonuclease: definition of a family of DNA repair enzymes. Proc. Natl. Acad. Sci. U. S. A., $88,11450-11454$.

25. Hadi, M. Z., Ginalski, K., Nguyen, L. H. and Wilson, D. M., III. (2002) Determinants in nuclease specificity of Ape1 and Ape2, human homologues of Escherichia coli exonuclease III. J. Mol. Biol., 316, 853-866.

26. Meira, L. B., Devaraj, S., Kisby, G. E., Burns, D. K., Daniel, R. L., Hammer, R. E., Grundy, S., Jialal, I. and Friedberg, E. C. (2001) Heterozygosity for the mouse Apex gene results in phenotypes associated with oxidative stress. Cancer Res., 61, 5552-5557.

27. Gorman, M. A., Morera, S., Rothwell, D. G., de La Fortelle, E., Mol, C. D., Tainer, J. A., Hickson, I. D. and Freemont, P. S. (1997) The crystal structure of the human DNA repair endonuclease HAP1 suggests the recognition of extra-helical deoxyribose at DNA abasic sites. EMBO J., 16, 6548-6558.

28. Tell, G., Quadrifoglio, F., Tiribelli, C. and Kelley, M. R. (2009) The many functions of APE1/Ref-1: not only a DNA repair enzyme. Antioxid. Redox Signal., 11, 601-620.

29. Whitaker, A. M. and Freudenthal, B. D. (2018) APE1: a skilled nucleic acid surgeon. DNA Repair (Amst)., 71, 93-100.

30. Erzberger, J. P. and Wilson, D. M., III. (1999) The role of $\mathrm{Mg}^{2+}$ and specific amino acid residues in the catalytic reaction of the major human abasic endonuclease: new insights from EDTA-resistant incision of acyclic abasic site analogs and site-directed mutagenesis. J. Mol. Biol., 290, 447-457.

31. Freudenthal, B. D., Beard, W. A., Cuneo, M. J., Dyrkheeva, N. S. and Wilson, S. H. (2015) Capturing snapshots of APE1 processing DNA damage. Nat. Struct. Mol. Biol., 22, 924-931.
32. Beernink, P. T., Segelke, B. W., Hadi, M. Z., Erzberger, J. P., Wilson, D. M., III and Rupp, B. (2001) Two divalent metal ions in the active site of a new crystal form of human apurinic/apyrimidinic endonuclease, Ape1: implications for the catalytic mechanism. J. Mol. Biol., 307, 1023-1034.

33. Mol, C. D., Izumi, T., Mitra, S. and Tainer, J. A. (2000) DNA-bound structures and mutants reveal abasic DNA binding by APE1 and DNA repair coordination [corrected]. Nature, 403, 451-456.

34. Marenstein, D. R., Wilson, D. M., III and Teebor, G. W. (2004) Human AP endonuclease (APE1) demonstrates endonucleolytic activity against AP sites in single-stranded DNA. DNA Repair (Amst)., 3, 527-533.

35. Chou, K. M. and Cheng, Y. C. (2003) The exonuclease activity of human apurinic/apyrimidinic endonuclease (APE1). Biochemical properties and inhibition by the natural dinucleotide Gp4G. J. Biol. Chem., 278, 1828918296.

36. Wilson, D. M. $3^{\text {rd }}$. (2003) Properties of and substrate determinants for the exonuclease activity of human apurinic endonuclease Ape1. J. Mol. Biol., 330, 1027-1037.

37. Izumi, T., Brown, D. B., Naidu, C. V., Bhakat, K. K., Macinnes, M. A., Saito, H., Chen, D. J. and Mitra, S. (2005) Two essential but distinct functions of the mammalian abasic endonuclease. Proc. Natl. Acad. Sci. U. S. A., 102, 5739-5743.

38. Fantini, D., Vascotto, C., Marasco, D., et al. (2010) Critical lysine residues within the overlooked N-terminal domain of human APE1 regulate its biological functions. Nucleic Acids Res., 38, 8239-8256.

39. Vascotto, C., Cesaratto, L., Zeef, L. A., et al. (2009) Genome-wide analysis and proteomic studies reveal APE1/Ref-1 multifunctional role in mammalian cells. Proteomics, 9, 1058-1074.

40. Vascotto, C., Lirussi, L., Poletto, M., et al. (2014) Functional regulation of the apurinic/apyrimidinic endonuclease 1 by nucleophosmin: impact on tumor biology. Oncogene, 33, 2876-2887.

41. Tell, G. and Demple, B. (2015) Base excision DNA repair and cancer. Oncotarget, 6, 584-585.

42. Busso, C. S., Iwakuma, T. and Izumi, T. (2009) Ubiquitination of mammalian AP endonuclease (APE1) regulated by the p53-MDM2 signaling pathway. Oncogene, 28, 1616-1625.

43. Huang, E., Qu, D., Zhang, Y., Venderova, K., Haque, M. E., Rousseaux, M. W., Slack, R. S., Woulfe, J. M. and Park, D. S. (2010) The role of $\mathrm{Cdk} 5$-mediated apurinic/apyrimidinic endonuclease 1 phosphorylation in neuronal death. Nat. Cell Biol., 12, 563-571.

44. Busso, C. S., Lake, M. W. and Izumi, T. (2010) Posttranslational modification of mammalian AP endonuclease (APE1). Cell. Mol. Life Sci., 67, 3609-3620.

45. Yoshida, A., Urasaki, Y., Waltham, M., et al. (2003) Human apurinic/ apyrimidinic endonuclease (Ape1) and its $\mathrm{N}$-terminal truncated form (AN34) are involved in DNA fragmentation during apoptosis. J. Biol. Chem., 278, 37768-37776.

46. Roychoudhury, S., Nath, S., Song, H., et al. (2017) Human apurinicl apyrimidinic endonuclease (APE1) is acetylated at DNA damage sites in chromatin, and acetylation modulates its DNA repair activity. Mol. Cell. Biol., 37, e00401-e00416.

47. Lirussi, L., Antoniali, G., Vascotto, C., et al. (2012) Nucleolar accumulation of APE1 depends on charged lysine residues that undergo acetylation upon genotoxic stress and modulate its BER activity in cells. Mol. Biol. Cell, 23, 4079-4096.

48. Burra, S., Marasco, D., Malfatti, M. C., Antoniali, G., Virgilio, A., Esposito, V., Demple, B., Galeone, A. and Tell, G. (2019) Human AP-endonuclease (Ape1) activity on telomeric G4 structures is modulated by acetylatable lysine residues in the $\mathrm{N}$-terminal sequence. DNA Repair (Amst)., 73, 129-143.

49. Sobol, R. W., Horton, J. K., Kühn, R., Gu, H., Singhal, R. K., Prasad, R., Rajewsky, K. and Wilson, S. H. (1996) Requirement of mammalian DNA polymerase-beta in base-excision repair. Nature, 379, 183-186.

50. Sung, J. S., DeMott, M. S. and Demple, B. (2005) Long-patch base excision DNA repair of 2-deoxyribonolactone prevents the formation of DNA-protein cross-links with DNA polymerase beta. J. Biol. Chem., 280, 39095-39103.

51. Wilson, S. H. and Kunkel, T. A. (2000) Passing the baton in base excision repair. Nat. Struct. Biol., 7, 176-178. 
52. Almeida, K. H. and Sobol, R. W. (2007) A unified view of base excision repair: lesion-dependent protein complexes regulated by post-translational modification. DNA Repair (Amst)., 6, 695-711.

53. Allinson, S. L., Sleeth, K. M., Matthewman, G. E. and Dianov, G. L. (2004) Orchestration of base excision repair by controlling the rates of enzymatic activities. DNA Repair (Amst)., 3, 23-31.

54. Déry, U. and Masson, J. Y. (2007) Twists and turns in the function of DNA damage signaling and repair proteins by post-translational modifications. DNA Repair (Amst)., 6, 561-577.

55. Fan, J. and Wilson, D. M., III. (2005) Protein-protein interactions and posttranslational modifications in mammalian base excision repair. Free Radic. Biol. Med., 38, 1121-1138.

56. Vascotto, C., Fantini, D., Romanello, M., et al. (2009) APE1/Ref-1 interacts with NPM1 within nucleoli and plays a role in the rRNA quality control process. Mol. Cell. Biol., 29, 1834-1854.

57. Khodyreva, S. N., Prasad, R., Ilina, E. S., Sukhanova, M. V., Kutuzov, M. M., Liu, Y., Hou, E. W., Wilson, S. H. and Lavrik, O. I. (2010) Apurinic/apyrimidinic (AP) site recognition by the 5'-dRP/AP lyase in poly(ADP-ribose) polymerase-1 (PARP-1). Proc. Natl. Acad. Sci. U. S. A., 107, 22090-22095.

58. Prasad, R., Dyrkheeva, N., Williams, J. and Wilson, S. H. (2015) Mammalian base excision repair: functional partnership between PARP-1 and APE1 in AP-site repair. PLoS One, 10, e0124269.

59. Alseth, I., Eide, L., Pirovano, M., Rognes, T., Seeberg, E. and Bjørås, M. (1999) The Saccharomyces cerevisiae homologues of endonuclease III from Escherichia coli, Ntg1 and Ntg2, are both required for efficient repair of spontaneous and induced oxidative DNA damage in yeast. Mol. Cell. Biol., 19, 3779-3787.

60. Blaisdell, J. O. and Wallace, S. S. (2001) Abortive base-excision repair of radiation-induced clustered DNA lesions in Escherichia coli. Proc. Natl. Acad. Sci. U. S. A., 98, 7426-7430.

61. Friedberg, E. C., Meira, L. B. and Cheo, D. L. (1997) Database of mouse strains carrying targeted mutations in genes affecting cellular responses to DNA damage. Mutat. Res., 383, 183-188.

62. Gros, L., Ishchenko, A. A., Ide, H., Elder, R. H. and Saparbaev, M. K. (2004) The major human AP endonuclease (APE1) is involved in the nucleotide incision repair pathway. Nucleic Acids Res., 32, 73-81.

63. Timofeyeva, N. A., Koval, V. V., Ishchenko, A. A., Saparbaev, M. K. and Fedorova, O. S. (2011) Lys98 substitution in human AP endonuclease 1 affects the kinetic mechanism of enzyme action in base excision and nucleotide incision repair pathways. PLoS One, 6, e24063.

64. Ishchenko, A. A., Deprez, E., Maksimenko, A., Brochon, J. C., Tauc, P. and Saparbaev, M. K. (2006) Uncoupling of the base excision and nucleotide incision repair pathways reveals their respective biological roles. Proc. Natl. Acad. Sci. U. S. A., 103, 2564-2569.

65. Gelin, A., Redrejo-Rodríguez, M., Laval, J., Fedorova, O. S., Saparbaev, M. and Ishchenko, A. A. (2010) Genetic and biochemical characterization of human AP endonuclease 1 mutants deficient in nucleotide incision repair activity. PLoS One, 5, e12241.

66. Daviet, S., Couvé-Privat, S., Gros, L., Shinozuka, K., Ide, H., Saparbaev, M. and Ishchenko, A. A. (2007) Major oxidative products of cytosine are substrates for the nucleotide incision repair pathway. DNA Repair (Amst)., 6, 8-18.

67. Redrejo-Rodríguez, M., Vigouroux, A., Mursalimov, A., et al. (2016) Structural comparison of AP endonucleases from the exonuclease III family reveals new amino acid residues in human AP endonuclease 1 that are involved in incision of damaged DNA. Biochimie, 128-129, 20-33.

68. Kim, K., Biade, S. and Matsumoto, Y. (1998) Involvement of flap endonuclease 1 in base excision DNA repair. J. Biol. Chem., 273, 8842-8848.

69. Klungland, A. and Lindahl, T. (1997) Second pathway for completion of human DNA base excision-repair: reconstitution with purified proteins and requirement for DNase IV (FEN1). EMBO J., 16, 3341-3348.

70. Ischenko, A. A. and Saparbaev, M. K. (2002) Alternative nucleotide incision repair pathway for oxidative DNA damage. Nature, 415, 183-187.

71. Ide, H., Tedzuka, K., Shimzu, H., Kimura, Y., Purmal, A. A., Wallace, S. S. and Kow, Y. W. (1994) Alpha-deoxyadenosine, a major anoxic radiolysis product of adenine in DNA, is a substrate for Escherichia coli endonuclease IV. Biochemistry, 33, 7842-7847.

72. Jorgensen, T. J., Furlong, E. A. and Henner, W. D. (1988) Gamma endonuclease of Micrococcus luteus: action on irradiated DNA. Radiat. Res., $114,556-566$.

73. Lesiak, K. B. and Wheeler, K. T. (1990) Formation of alpha-deoxyadenosine in polydeoxynucleotides exposed to ionizing radiation under anoxic conditions. Radiat. Res., 121, 328-337.

74. Dizdaroglu, M., Laval, J. and Boiteux, S. (1993) Substrate specificity of the Escherichia coli endonuclease III: excision of thymine- and cytosinederived lesions in DNA produced by radiation-generated free radicals. Biochemistry, 32, 12105-12111.

75. Ishchenko, A. A., Ide, H., Ramotar, D., Nevinsky, G. and Saparbaev, M. (2004) Alpha-anomeric deoxynucleotides, anoxic products of ionizing radiation, are substrates for the endonuclease IV-type AP endonucleases. Biochemistry, 43, 15210-15216.

76. Abad, J. P. and Villasante, A. (1999) The 3' non-coding region of the Drosophila melanogaster HeT-A telomeric retrotransposon contains sequences with propensity to form G-quadruplex DNA. FEBS Lett., 453, 59-62.

77. Moyzis, R. K., Buckingham, J. M., Cram, L. S., Dani, M., Deaven, L. L., Jones, M. D., Meyne, J., Ratliff, R. L. and Wu, J. R. (1988) A highly conserved repetitive DNA sequence, (TTAGGG)n, present at the telomeres of human chromosomes. Proc. Natl. Acad. Sci. U. S. A., 85, 6622-6626.

78. de Lange, T. (2005) Shelterin: the protein complex that shapes and safeguards human telomeres. Genes Dev., 19, 2100-2110.

79. Oganesian, L. and Karlseder, J. (2009) Telomeric armor: the layers of end protection. J. Cell Sci., 122, 4013-4025.

80. Huppert, J. L. (2008) Four-stranded nucleic acids: structure, function and targeting of G-quadruplexes. Chem. Soc. Rev., 37, 1375-1384.

81. Fleming, A. M. and Burrows, C. J. (2013) G-quadruplex folds of the human telomere sequence alter the site reactivity and reaction pathway of guanine oxidation compared to duplex DNA. Chem. Res. Toxicol., 26, 593-607.

82. Zhou, J., Liu, M., Fleming, A. M., Burrows, C. J. and Wallace, S. S. (2013) Neil3 and NEIL1 DNA glycosylases remove oxidative damages from quadruplex DNA and exhibit preferences for lesions in the telomeric sequence context. J. Biol. Chem., 288, 27263-27272.

83. Zhou, J., Fleming, A. M., Averill, A. M., Burrows, C. J. and Wallace, S. S. (2015) The NEIL glycosylases remove oxidized guanine lesions from telomeric and promoter quadruplex DNA structures. Nucleic Acids Res., 43, 4039-4054.

84. Zhou, J., Chan, J., Lambelé, M., Yusufzai, T., Stumpff, J., Opresko, P. L., Thali, M. and Wallace, S. S. (2017) NEIL3 repairs telomere damage during S phase to secure chromosome segregation at mitosis. Cell Rep., 20, 20442056.

85. Li, M., Yang, X., Lu, X., et al. (2018) APE1 deficiency promotes cellular senescence and premature aging features. Nucleic Acids Res., 46, 56645677 .

86. Madlener, S., Ströbel, T., Vose, S., Saydam, O., Price, B. D., Demple, B. and Saydam, N. (2013) Essential role for mammalian apurinic/apyrimidinic (AP) endonuclease Ape1/Ref-1 in telomere maintenance. Proc. Natl. Acad. Sci. U. S. A., 110, 17844-17849.

87. Stavnezer, J., Guikema, J. E. and Schrader, C. E. (2008) Mechanism and regulation of class switch recombination. Annu. Rev. Immunol., 26, 261-292.

88. Masani, S., Han, L. and Yu, K. (2013) Apurinic/apyrimidinic endonuclease 1 is the essential nuclease during immunoglobulin class switch recombination. Mol. Cell. Biol., 33, 1468-1473.

89. Schrader, C. E., Guikema, J. E., Wu, X. and Stavnezer, J. (2009) The roles of APE1, APE2, DNA polymerase beta and mismatch repair in creating $\mathrm{S}$ region DNA breaks during antibody class switch. Philos. Trans. R. Soc. Lond. B. Biol. Sci., 364, 645-652.

90. Guikema, J. E. J., Linehan, E. K., Tsuchimoto, D., Nakabeppu, Y., Strauss, P. R., Stavnezer, J. and Schrader, C. E. (2008) APE1- and APE2dependent DNA breaks in immunoglobulin class switch recombination. J. Exp. Med., 204,3295-3295. 
91. Akbari, M., Otterlei, M., Peña-Diaz, J., et al. (2004) Repair of U/G and U/A in DNA by UNG2-associated repair complexes takes place predominantly by short-patch repair both in proliferating and growtharrested cells. Nucleic Acids Res., 32, 5486-5498.

92. Vuong, B. Q., Herrick-Reynolds, K., Vaidyanathan, B., et al. (2013) A DNA break- and phosphorylation-dependent positive feedback loop promotes immunoglobulin class-switch recombination. Nat. Immunol., 14, 1183-1189.

93. Vuong, B. Q. and Chaudhuri, J. (2012) Combinatorial mechanisms regulating AID-dependent DNA deamination: interacting proteins and post-translational modifications. Semin. Immunol., 24, 264-272.

94. Xu, J., Husain, A., Hu, W., Honjo, T. and Kobayashi, M. (2014) APE1 is dispensable for S-region cleavage but required for its repair in class switch recombination. Proc. Natl. Acad. Sci. U. S. A., 111, 1724217247.

95. Islam, H., Kobayashi, M. and Honjo, T. (2019) Apurinic/apyrimidinic endonuclease 1 (APE1) is dispensable for activation-induced cytidine deaminase (AID)-dependent somatic hypermutation in the immunoglobulin gene. Int. Immunol., 31, 543-554.

96. Gostissa, M., Alt, F. W. and Chiarle, R. (2011) Mechanisms that promote and suppress chromosomal translocations in lymphocytes. Апnи. Rev. Immunol., 29, 319-350.

97. Tell, G., Fantini, D. and Quadrifoglio, F. (2010) Understanding different functions of mammalian AP endonuclease (APE1) as a promising tool for cancer treatment. Cell. Mol. Life Sci., 67, 3589-3608.

98. Antoniali, G., Lirussi, L., D’Ambrosio, C., et al. (2014) SIRT1 gene expression upon genotoxic damage is regulated by APE1 through nCaREpromoter elements. Mol. Biol. Cell, 25, 532-547.

99. Frossi, B., Antoniali, G., Yu, K., Akhtar, N., Kaplan, M. H., Kelley, M. R., Tell, G. and Pucillo, C. E. M. (2019) Endonuclease and redox activities of human apurinic/apyrimidinic endonuclease 1 have distinctive and essential functions in IgA class switch recombination. $J$. Biol. Chem., 294, 5198-5207.

100. Fong, Y. W., Cattoglio, C. and Tjian, R. (2013) The intertwined roles of transcription and repair proteins. Mol. Cell, 52, 291-302.

101. Fleming, A. M., Ding, Y. and Burrows, C. J. (2017) Oxidative DNA damage is epigenetic by regulating gene transcription via base excision repair. Proc. Natl. Acad. Sci. U. S. A., 114, 2604-2609.

102. Fleming, A. M. and Burrows, C. J. (2017) 8-Oxo-7,8-dihydroguanine, friend and foe: epigenetic-like regulator versus initiator of mutagenesis. DNA Repair (Amst)., 56, 75-83.

103. Dizdaroglu, M. (2012) Oxidatively induced DNA damage: mechanisms, repair and disease. Cancer Lett., 327, 26-47.

104. Kumar, S., Chinnusamy, V. and Mohapatra, T. (2018) Epigenetics of modified DNA bases: 5-methylcytosine and beyond. Front. Genet., 9, 640.

105. Jena, N. R. and Mishra, P. C. (2005) Mechanisms of formation of 8-oxoguanine due to reactions of one and two $\mathrm{OH}^{*}$ radicals and the $\mathrm{H}_{2} \mathrm{O}_{2}$ molecule with guanine: a quantum computational study. J. Phys. Chem. B, 109, 14205-14218.

106. Zarakowska, E., Gackowski, D., Foksinski, M. and Olinski, R. (2014) Are 8-oxoguanine (8-oxoGua) and 5-hydroxymethyluracil (5-hmUra) oxidatively damaged DNA bases or transcription (epigenetic) marks? Mutat. Res. Genet. Toxicol. Environ. Mutagen., 764-765, 58-63.

107. Nakabeppu, Y., Tsuchimoto, D., Yamaguchi, H. and Sakumi, K. (2007) Oxidative damage in nucleic acids and Parkinson's disease. J. Neurosci. Res., 85, 919-934.

108. Moreira, P. I., Nunomura, A., Nakamura, M., Takeda, A., Shenk, J. C., Aliev, G., Smith, M. A. and Perry, G. (2008) Nucleic acid oxidation in Alzheimer disease. Free Radic. Biol. Med., 44, 1493-1505.

109. Sliwinska, A., Kwiatkowski, D., Czarny, P., et al. (2016) The levels of 7,8-dihydrodeoxyguanosine (8-oxoG) and 8-oxoguanine DNA glycosylase 1 (OGG1)—a potential diagnostic biomarkers of Alzheimer's disease. J. Neurol. Sci., 368, 155-159.

110. Pan, L., Zhu, B., Hao, W., et al. (2016) Oxidized guanine base lesions function in 8-oxoguanine DNA glycosylase-1-mediated epigenetic regu- lation of nuclear factor $\mathrm{\kappa B}$-driven gene expression. J. Biol. Chem., 291, 25553-25566.

111. Ba, X. and Boldogh, I. (2018) 8-Oxoguanine DNA glycosylase 1: beyond repair of the oxidatively modified base lesions. Redox Biol., 14, 669-678.

112. Tornaletti, S. (2005) Transcription arrest at DNA damage sites. Mutat. Res., 577, 131-145.

113. Allgayer, J., Kitsera, N., Bartelt, S., Epe, B. and Khobta, A. (2016) Widespread transcriptional gene inactivation initiated by a repair intermediate of 8-oxoguanine. Nucleic Acids Res., 44, 7267-7280.

114. Ramon, O., Sauvaigo, S., Gasparutto, D., Faure, P., Favier, A. and Cadet, J. (1999) Effects of 8-oxo-7,8-dihydro-2'-deoxyguanosine on the binding of the transcription factor $\mathrm{Sp} 1$ to its cognate target DNA sequence (GC box). Free Radic. Res., 31, 217-229.

115. Hailer-Morrison, M. K., Kotler, J. M., Martin, B. D. and Sugden, K. D. (2003) Oxidized guanine lesions as modulators of gene transcription. Altered p50 binding affinity and repair shielding by 7,8-dihydro-8-oxo2 '-deoxyguanosine lesions in the NF-kappaB promoter element. Biochemistry, 42, 9761-9770.

116. Moore, S. P., Toomire, K. J. and Strauss, P. R. (2013) DNA modifications repaired by base excision repair are epigenetic. DNA Repair (Amst)., 12, 1152-1158.

117. Perillo, B., Ombra, M. N., Bertoni, A., et al. (2008) DNA oxidation as triggered by $\mathrm{H} 3 \mathrm{~K} 9 \mathrm{me} 2$ demethylation drives estrogen-induced gene expression. Science, 319, 202-206.

118. Pastukh, V., Roberts, J. T., Clark, D. W., Bardwell, G. C., Patel, M., Al-Mehdi, A. B., Borchert, G. M. and Gillespie, M. N. (2015) An oxidative DNA "damage" and repair mechanism localized in the VEGF promoter is important for hypoxia-induced VEGF mRNA expression. Am. J. Physiol. Lung Cell. Mol. Physiol., 309, L1367-L1375.

119. Fleming, A. M., Zhu, J., Ding, Y. and Burrows, C. J. (2017) 8-Oxo-7,8dihydroguanine in the context of a gene promoter G-quadruplex is an on-off switch for transcription. ACS Chem. Biol., 12, 2417-2426.

120. Pan, L., Hao, W., Zheng, X., Zeng, X., Ahmed Abbasi, A., Boldogh, I. and Ba, X. (2017) OGG1-DNA interactions facilitate NF- $\kappa B$ binding to DNA targets. Sci. Rep., 7, 43297.

121. Mabley, J. G., Pacher, P., Deb, A., Wallace, R., Elder, R. H. and Szabó, C. (2005) Potential role for 8-oxoguanine DNA glycosylase in regulating inflammation. FASEB J., 19, 290-292.

122. Li, G., Yuan, K., Yan, C., et al. (2012) 8-Oxoguanine-DNA glycosylase 1 deficiency modifies allergic airway inflammation by regulating STAT6 and IL-4 in cells and in mice. Free Radic. Biol. Med., 52, 392-401.

123. Fleming, A. M., Zhu, J., Ding, Y., Esders, S. and Burrows, C. J. (2019) Oxidative modification of guanine in a potential Z-DNA-forming sequence of a gene promoter impacts gene expression. Chem. Res. Toxicol., 32, 899-909.

124. Zhu, J., Fleming, A. M. and Burrows, C. J. (2018) The RAD17 promoter sequence contains a potential tail-dependent G-quadruplex that downregulates gene expression upon oxidative modification. ACS Chem. Biol., 13, 2577-2584.

125. Redstone, S. C. J., Fleming, A. M. and Burrows, C. J. (2019) Oxidative modification of the potential G-quadruplex sequence in the PCNA gene promoter can turn on transcription. Chem. Res. Toxicol., 32, 437-446.

126. Fleming, A. M., Zhu, J., Howpay Manage, S. A., and Burrows, C. J. (2019) Human NEIL3 gene expression regulated by epigenetic-like oxidative DNA modification. J. Am. Chem. Soc, 141, 11036-11049.

127. Fleming, A. M., Zhu, J., Ding, Y., Visser, J. A., Zhu, J. and Burrows, C. J. (2018) Human DNA repair genes possess potential G-quadruplex sequences in their promoters and 5'-untranslated regions. Biochemistry, 57, 991-1002.

128. Gautier, C. (2000) Compositional bias in DNA. Curr. Opin. Genet. Dev., 10, 656-661.

129. Forneris, F., Binda, C., Vanoni, M. A., Mattevi, A. and Battaglioli, E. (2005) Histone demethylation catalysed by LSD1 is a flavin-dependent oxidative process. FEBS Lett., 579, 2203-2207.

130. Boldogh, I., Hajas, G., Aguilera-Aguirre, L., Hegde, M. L., Radak, Z., Bacsi, A., Sur, S., Hazra, T. K. and Mitra, S. (2012) Activation of ras 
signaling pathway by 8-oxoguanine DNA glycosylase bound to its excision product, 8-oxoguanine. J. Biol. Chem., 287, 20769-20773.

131. Vohhodina, J., Harkin, D. P. and Savage, K. I. (2016) Dual roles of DNA repair enzymes in RNA biology/post-transcriptional control. Wiley Interdiscip. Rev. RNA, 7, 604-619.

132. Jobert, L. and Nilsen, H. (2014) Regulatory mechanisms of RNA function: emerging roles of DNA repair enzymes. Cell. Mol. Life Sci., 71, 2451-2465.

133. Antoniali, G., Malfatti, M. C. and Tell, G. (2017) Unveiling the nonrepair face of the base excision repair pathway in RNA processing: a missing link between DNA repair and gene expression? DNA Repair (Amst)., 56, 65-74.

134. Tell, G., Wilson, D. M., III and Lee, C. H. (2010) Intrusion of a DNA repair protein in the RNome world: is this the beginning of a new era? Mol. Cell. Biol., 30, 366-371.

135. Poletto, M., Vascotto, C., Scognamiglio, P. L., Lirussi, L., Marasco, D. and Tell, G. (2013) Role of the unstructured N-terminal domain of the hAPE1 (human apurinic/apyrimidinic endonuclease 1) in the modulation of its interaction with nucleic acids and NPM1 (nucleophosmin). Biochem. J., 452, 545-557.

136. Chohan, M., Mackedenski, S., Li, W. M. and Lee, C. H. (2015) Human apurinic/apyrimidinic endonuclease 1 (APE1) has 3' RNA phosphatase and 3' exoribonuclease activities. J. Mol. Biol., 427, 298-311.

137. Zhang, C. and Peng, G. (2015) Non-coding RNAs: an emerging player in DNA damage response. Mutat. Res. Rev. Mutat. Res., 763, 202-211.

138. D'Adda di Fagagna, F. (2014) A direct role for small non-coding RNAs in DNA damage response. Trends Cell Biol., 24,171-178.

139. Su, M., Wang, H., Wang, W., Wang, Y., Ouyang, L., Pan, C., Xia, L., Cao, D. and Liao, Q. (2018) LncRNAs in DNA damage response and repair in cancer cells. Acta Biochim. Biophys. Sin. (Shanghai)., 50, 433-439.

140. Poletto, M., Lirussi, L., Wilson, D. M., III and Tell, G. (2014) Nucleophosmin modulates stability, activity, and nucleolar accumulation of base excision repair proteins. Mol. Biol. Cell, 25, 1641-1652.

141. Di Maso, V., Avellini, C., Crocè, L. S., et al. (2007) Subcellular localization of APE1/Ref-1 in human hepatocellular carcinoma: possible prognostic significance. Mol. Med., 13, 89-96.

142. Nunomura, A., Moreira, P. I., Castellani, R. J., Lee, H. G., Zhu, X., Smith, M. A. and Perry, G. (2012) Oxidative damage to RNA in aging and neurodegenerative disorders. Neurotox. Res., 22, 231-248.

143. Förstemann, K. and Lingner, J. (2005) Telomerase limits the extent of base pairing between template RNA and telomeric DNA. EMBO Rep., 6, 361-366.

144. Kahl, G. (2015) DNA-RNA hybrid. The Dictionary of Genomics, Transcriptomics and Proteomics. The Dictionary of Genomics, Transcriptomics and Proteomics Science, pp. 1-1.

145. Hamperl, S. and Cimprich, K. A. (2014) The contribution of co-transcriptional RNA:DNA hybrid structures to DNA damage and genome instability. DNA Repair (Amst)., 19, 84-94.

146. Brambati, A., Colosio, A., Zardoni, L., Galanti, L. and Liberi, G. (2015) Replication and transcription on a collision course: eukaryotic regulation mechanisms and implications for DNA stability. Front. Genet., 6, 166.

147. Sassa, A., Yasui, M., and Honma, M. (2019) Current perspectives on mechanisms of ribonucleotide incorporation and processing in mammalian DNA. Genes Environ., 41, 3.

148. Williams, J. S. and Kunkel, T. A. (2014) Ribonucleotides in DNA: origins, repair and consequences. DNA Repair (Amst)., 19, 27-37.

149. Koh, K. D., Balachander, S., Hesselberth, J. R. and Storici, F. (2015) Ribose-seq: global mapping of ribonucleotides embedded in genomic DNA. Nat. Methods, 12, 251-257.

150. Hovatter, K. R. and Martinson, H. G. (1987) Ribonucleotide-induced helical alteration in DNA prevents nucleosome formation. Proc. Natl. Acad. Sci. U. S. A., 84, 1162-1166.

151. Potenski, C. J. and Klein, H. L. (2014) How the misincorporation of ribonucleotides into genomic DNA can be both harmful and helpful to cells. Nucleic Acids Res., 42, 10226-10234.
152. Kind, B., Wolf, C., Engel, K., Rapp, A., Cristina Cardoso, M. and LeeKirsch, M. A. (2018) Single cell gel electrophoresis for the detection of genomic ribonucleotides. Methods Mol. Biol., 1672, 311-318.

153. Meroni, A., Nava, G. M., Sertic, S., Plevani, P., Muzi-Falconi, M. and Lazzaro, F. (2018) Measuring the levels of ribonucleotides embedded in genomic DNA. Methods Mol. Biol., 1672, 319-327.

154. Li, Z., Zhang, H. X., Li, Y., et al. (2019) Method for quantification of ribonucleotides and deoxyribonucleotides in human cells using (trimethylsilyl)diazomethane derivatization followed by liquid chromatography-tandem mass spectrometry. Anal. Chem., 91, 10191026.

155. Zhou, Z.-X., Williams, J. S. and Kunkel, T. A. (2018) Studying ribonucleotide incorporation: strand-specific detection of ribonucleotides in the yeast genome and measuring ribonucleotideinduced mutagenesis. J. Vis. Exp, 58020.

156. Jinks-Robertson, S. and Klein, H. L. (2015) Ribonucleotides in DNA: hidden in plain sight. Nat. Struct. Mol. Biol., 22, 176-178.

157. Gombolay, A. L., Vannberg, F. O. and Storici, F. (2019) Ribose-Map: a bioinformatics toolkit to map ribonucleotides embedded in genomic DNA. Nucleic Acids Res., 47, e5.

158. Clausen, A. R., Lujan, S. A., Burkholder, A. B., et al. (2015) Tracking replication enzymology in vivo by genome-wide mapping of ribonucleotide incorporation. Nat. Struct. Mol. Biol., 22, 185-191.

159. Daigaku, Y., Keszthelyi, A., Müller, C. A., Miyabe, I., Brooks, T., Retkute, R., Hubank, M., Nieduszynski, C. A. and Carr, A. M. (2015) A global profile of replicative polymerase usage. Nat. Struct. Mol. Biol., 22, 192-198.

160. Reijns, M. A., Rabe, B., Rigby, R. E., et al. (2012) Enzymatic removal of ribonucleotides from DNA is essential for mammalian genome integrity and development. Cell, 149, 1008-1022.

161. Nick McElhinny, S. A., Kumar, D., Clark, A. B., Watt, D. L., Watts, B. E., Lundström, E. B., Johansson, E., Chabes, A. and Kunkel, T. A. (2010) Genome instability due to ribonucleotide incorporation into DNA. Nat. Chem. Biol., 6, 774-781.

162. Joyce, C. M. (1997) Choosing the right sugar: how polymerases select a nucleotide substrate. Proc. Natl. Acad. Sci. U. S. A., 94, 1619-1622.

163. Brown, J. A. and Suo, Z. (2011) Unlocking the sugar "steric gate" of DNA polymerases. Biochemistry, 50, 1135-1142.

164. Nick McElhinny, S. A., Watts, B. E., Kumar, D., Watt, D. L., Lundström, E. B., Burgers, P. M., Johansson, E., Chabes, A. and Kunkel, T. A. (2010) Abundant ribonucleotide incorporation into DNA by yeast replicative polymerases. Proc. Natl. Acad. Sci. U. S. A., 107, 4949-4954.

165. Marasco, M., Li, W., Lynch, M. and Pikaard, C. S. (2017) Catalytic properties of RNA polymerases IV and V: accuracy, nucleotide incorporation and rNTP/dNTP discrimination. Nucleic Acids Res., 45, 11315-11326.

166. Vaisman, A. and Woodgate, R. (2018) Ribonucleotide discrimination by translesion synthesis DNA polymerases. Crit. Rev. Biochem. Mol. Biol., 53, 382-402.

167. Clausen, A. R., Zhang, S., Burgers, P. M., Lee, M. Y. and Kunkel, T. A. (2013) Ribonucleotide incorporation, proofreading and bypass by human DNA polymerase $\delta$. DNA Repair (Amst)., 12, 121-127.

168. Rossi, M. L. and Bambara, R. A. (2006) Reconstituted Okazaki fragment processing indicates two pathways of primer removal. J. Biol. Chem., 281, 26051-26061.

169. Chiu, H. C., Koh, K. D., Evich, M., Lesiak, A. L., Germann, M. W., Bongiorno, A., Riedo, E. and Storici, F. (2014) RNA intrusions change DNA elastic properties and structure. Nanoscale, 6, 10009-10017.

170. Koh, K. D., Chiu, H. C., Riedo, E. and Storici, F. (2015) Measuring the elasticity of ribonucleotide(s)-containing DNA molecules using AFM. Methods Mol. Biol., 1297, 43-57.

171. Evich, M., Spring-Connell, A. M., Storici, F. and Germann, M. W. (2016) Structural impact of single ribonucleotide residues in DNA. Chembiochem, 17, 1968-1977.

172. Klein, H. L. (2017) Genome instabilities arising from ribonucleotides in DNA. DNA Repair (Amst)., 56, 26-32. 
173. Fu, I., Smith, D. J. and Broyde, S. (2019) Rotational and translational positions determine the structural and dynamic impact of a single ribonucleotide incorporated in the nucleosome. DNA Repair (Amst)., 73, 155-163.

174. Meroni, A., Mentegari, E., Crespan, E., Muzi-Falconi, M., Lazzaro, F. and Podestà, A. (2017) The incorporation of ribonucleotides induces structural and conformational changes in DNA. Biophys. J., 113, 13731382.

175. Sparks, J. L., Chon, H., Cerritelli, S. M., Kunkel, T. A., Johansson, E., Crouch, R. J. and Burgers, P. M. (2012) RNase H2-initiated ribonucleotide excision repair. Mol. Cell, 47, 980-986.

176. Rydberg, B. and Game, J. (2002) Excision of misincorporated ribonucleotides in DNA by RNase $\mathrm{H}$ (type 2) and FEN-1 in cell-free extracts. Proc. Natl. Acad. Sci. U. S. A., 99, 16654-16659.

177. Hiller, B., Achleitner, M., Glage, S., Naumann, R., Behrendt, R. and Roers, A. (2012) Mammalian RNase H2 removes ribonucleotides from DNA to maintain genome integrity. J. Exp. Med., 209, 1419-1426.

178. Cerritelli, S. M. and Crouch, R. J. (2009) Ribonuclease H: the enzymes in eukaryotes. FEBS J., 276, 1494-1505.

179. Lazzaro, F., Novarina, D., Amara, F., et al. (2012) RNase H and postreplication repair protect cells from ribonucleotides incorporated in DNA. Mol. Cell, 45, 99-110.

180. Pizzi, S., Sertic, S., Orcesi, S., Cereda, C., Bianchi, M., Jackson, A. P., Lazzaro, F., Plevani, P. and Muzi-Falconi, M. (2015) Reduction of hRNase H2 activity in Aicardi-Goutières syndrome cells leads to replication stress and genome instability. Hum. Mol. Genet., 24, 649-658.

181. Crow, Y. J., Leitch, A., Hayward, B. E., et al. (2006) Mutations in genes encoding ribonuclease $\mathrm{H} 2$ subunits cause Aicardi-Goutières syndrome and mimic congenital viral brain infection. Nat. Genet., 38, 910-916.

182. Rabe, B. (2013) Aicardi-Goutières syndrome: clues from the RNase H2 knock-out mouse. J. Mol. Med. (Berl)., 91, 1235-1240.

183. Brzostek-Racine, S., Gordon, C., Van Scoy, S. and Reich, N. C. (2011) The DNA damage response induces IFN. J. Immunol., 187, 5336-5345.

184. Tsukiashi, M., Baba, M., Kojima, K., Himeda, K., Takita, T. and Yasukawa, K. (2019) Construction and characterization of ribonuclease H2 knockout NIH3T3 cells. J. Biochem., 165, 249-256.

185. Uehara, R., Cerritelli, S. M., Hasin, N., Sakhuja, K., London, M., Iranzo, J., Chon, H., Grinberg, A. and Crouch, R. J. (2018) Two RNase $\mathrm{H} 2$ mutants with differential rNMP processing activity reveal a threshold of ribonucleotide tolerance for embryonic development. Cell Rep., 25, 1135-1145.e5.

186. Mottaghi-Dastjerdi, N., Soltany-Rezaee-Rad, M., Sepehrizadeh, Z., Roshandel, G., Ebrahimifard, F. and Setayesh, N. (2015) Identification of novel genes involved in gastric carcinogenesis by suppression subtractive hybridization. Hum. Exp. Toxicol., 34, 3-11.

187. Aden, K., Bartsch, K., Dahl, J., et al. (2019) Epithelial RNase H2 maintains genome integrity and prevents intestinal tumorigenesis in mice. Gastroenterology, 156, 145.e19-159.e19.

188. Hiller, B., Hoppe, A., Haase, C., et al. (2018) Ribonucleotide excision repair is essential to prevent squamous cell carcinoma of the skin. Cancer Res., 78, 5917-5926.

189. Sayrac, S., Vengrova, S., Godfrey, E. L. and Dalgaard, J. Z. (2011) Identification of a novel type of spacer element required for imprinting in fission yeast. PLoS Genet., 7, e1001328.

190. Brown, J. A., Fiala, K. A., Fowler, J. D., Sherrer, S. M., Newmister, S. A., Duym, W. W. and Suo, Z. (2010) A novel mechanism of sugar selection utilized by a human X-family DNA polymerase. J. Mol. Biol., 395, 282-290.

191. Ruiz, J. F., Juárez, R., García-Díaz, M., Terrados, G., Picher, A. J., González-Barrera, S., Fernández de Henestrosa, A. R. and Blanco, L. (2003) Lack of sugar discrimination by human Pol mu requires a single glycine residue. Nucleic Acids Res., 31, 4441-4449.

192. Martin, M. J., Garcia-Ortiz, M. V., Esteban, V. and Blanco, L. (2013) Ribonucleotides and manganese ions improve non-homologous end joining by human Pol $\mu$. Nucleic Acids Res., 41, 2428-2436.

193. Nick McElhinny, S. A. and Ramsden, D. A. (2003) Polymerase mu is a DNA-directed DNA/RNA polymerase. Mol. Cell. Biol., 23, 23092315 .
194. Lujan, S. A., Williams, J. S., Clausen, A. R., Clark, A. B. and Kunkel, T. A. (2013) Ribonucleotides are signals for mismatch repair of leading-strand replication errors. Mol. Cell, 50, 437-443.

195. Storici, F., Bebenek, K., Kunkel, T. A., Gordenin, D. A. and Resnick, M. A. (2007) RNA-templated DNA repair. Nature, 447, 338341.

196. Shen, Y., Nandi, P., Taylor, M. B., Stuckey, S., Bhadsavle, H. P., Weiss, B. and Storici, F. (2011) RNA-driven genetic changes in bacteria and in human cells. Mutat. Res., 717, 91-98.

197. Shen, Y., Koh, K. D., Weiss, B. and Storici, F. (2011) Mispaired rNMPs in DNA are mutagenic and are targets of mismatch repair and RNases H. Nat. Struct. Mol. Biol., 19, 98-104.

198. Williams, J. S., Lujan, S. A. and Kunkel, T. A. (2016) Processing ribonucleotides incorporated during eukaryotic DNA replication. Nat. Rev. Mol. Cell Biol., 17, 350-363.

199. Williams, J. S., Smith, D. J., Marjavaara, L., Lujan, S. A., Chabes, A. and Kunkel, T. A. (2013) Topoisomerase 1-mediated removal of ribonucleotides from nascent leading-strand DNA. Mol. Cell, 49, 10101015.

200. Capranico, G., Marinello, J. and Chillemi, G. (2017) Type I DNA topoisomerases. J. Med. Chem., 60, 2169-2192.

201. Cho, J. E. and Jinks-Robertson, S. (2018) Topoisomerase I and genome stability: the good and the bad. Methods Mol. Biol., 1703, 21-45.

202. Williams, J. S. and Kunkel, T. A. (2018) Studying topoisomerase 1-mediated damage at genomic ribonucleotides. Methods Mol. Biol., 1703, 241-257.

203. Sekiguchi, J. and Shuman, S. (1997) Site-specific ribonuclease activity of eukaryotic DNA topoisomerase I. Mol. Cell, 1, 89-97.

204. Potenski, C. J., Niu, H., Sung, P. and Klein, H. L. (2014) Avoidance of ribonucleotide-induced mutations by RNase H2 and Srs2-Exo1 mechanisms. Nature, 511, 251-254.

205. Kim, N., Huang, S. N., Williams, J. S., Li, Y. C., Clark, A. B., Cho, J. E., Kunkel, T. A., Pommier, Y. and Jinks-Robertson, S. (2011) Mutagenic processing of ribonucleotides in DNA by yeast topoisomerase I. Science, $332,1561-1564$

206. Li, F., Wang, Q., Seol, J. H., Che, J., Lu, X., Shim, E. Y., Lee, S. E. and Niu, H. (2019) Apn2 resolves blocked 3' ends and suppresses Top1induced mutagenesis at genomic rNMP sites. Nat. Struct. Mol. Biol., 26, 155-163.

207. Zimmermann, M., Murina, O., Reijns, M. A. M., et al. (2018) CRISPR screens identify genomic ribonucleotides as a source of PARP-trapping lesions. Nature, 559, 285-289.

208. Lindsey-Boltz, L. A., Kemp, M. G., Hu, J. and Sancar, A. (2015) Analysis of ribonucleotide removal from DNA by human nucleotide excision repair. J. Biol. Chem., 290, 29801-29807.

209. Reardon, J. T. and Sancar, A. (2005) Nucleotide excision repair. Prog. Nucleic Acid Res. Mol. Biol., 79, 183-235.

210. Vaisman, A., McDonald, J. P., Huston, D., Kuban, W., Liu, L., Van Houten, B. and Woodgate, R. (2013) Removal of misincorporated ribonucleotides from prokaryotic genomes: an unexpected role for nucleotide excision repair. PLoS Genet., 9, e1003878.

211. Cai, Y., Geacintov, N. E. and Broyde, S. (2014) Ribonucleotides as nucleotide excision repair substrates. DNA Repair (Amst)., 13, 55-60.

212. Randerath, K., Reddy, R., Danna, T. F., Watson, W. P., Crane, A. E. and Randerath, E. (1992) Formation of ribonucleotides in DNA modified by oxidative damage in vitro and in vivo. Characterization by 32P-postlabeling. Mutat. Res., 275, 355-366.

213. Kuznetsov, N. A., Koval, V. V., Zharkov, D. O., Nevinsky, G. A., Douglas, K. T. and Fedorova, O. S. (2005) Kinetics of substrate recognition and cleavage by human 8-oxoguanine-DNA glycosylase. Nucleic Acids Res., 33, 3919-3931.

214. Yamagata, Y. (2011) Structural basis for the recognition and removal of damaged bases from DNA by a DNA repair enzyme, 3-methyladenine DNA glycosylase from Escherichia coli. Nihon Kessho Gakkaishi, 39,303-308.

215. Fromme, J. C., Bruner, S. D., Yang, W., Karplus, M. and Verdine, G. L. (2003) Product-assisted catalysis in base-excision DNA repair. Nat. Struct. Biol., 10, 204-211. 
216. Malfatti, M. C., Henneke, G., Balachander, S., Koh, K. D., Newnam, G., Uehara, R., Crouch, R. J., Storici, F. and Tell, G. (2019) Unlike the Escherichia coli counterpart, archaeal RNase HII cannot process ribose monophosphate abasic sites and oxidized ribonucleotides embedded in DNA. J. Biol. Chem., 294, 13061-13072.

217. Berglund, A. K., Navarrete, C., Engqvist, M. K., Hoberg, E., Szilagyi, Z., Taylor, R. W., Gustafsson, C. M., Falkenberg, M. and Clausen, A. R. (2017) Nucleotide pools dictate the identity and frequency of ribonucleotide incorporation in mitochondrial DNA. PLoS Genet., 13, e1006628.

218. Kreisel, K., Engqvist, M. K. M. and Clausen, A. R. (2017) Simultaneous mapping and quantitation of ribonucleotides in human mitochondrial DNA. J. Vis. Exp., 56551.

219. Moss, C. F., Dalla Rosa, I., Hunt, L. E., et al. (2017) Aberrant ribonucleotide incorporation and multiple deletions in mitochondrial DNA of the murine MPV17 disease model. Nucleic Acids Res., 45, 12808-12815.

220. Forslund, J. M. E., Pfeiffer, A., Stojkovič, G., Wanrooij, P. H. and Wanrooij, S. (2018) The presence of rNTPs decreases the speed of mitochondrial DNA replication. PLoS Genet., 14, e1007315.

221. Wanrooij, P. H., Engqvist, M. K. M., Forslund, J. M. E., Navarrete, C., Nilsson, A. K., Sedman, J., Wanrooij, S., Clausen, A. R. and Chabes, A. (2017) Ribonucleotides incorporated by the yeast mitochondrial DNA polymerase are not repaired. Proc. Natl. Acad. Sci. U. S. A., 114, 12466-12471.

222. Leguisamo, N. M., Gloria, H. C., Kalil, A. N., Martins, T. V., Azambuja, D. B., Meira, L. B. and Saffi, J. (2017) Base excision repair imbalance in colorectal cancer has prognostic value and modulates response to chemotherapy. Oncotarget, 8, 54199-54214.

223. Shah, F., Logsdon, D., Messmann, R. A., Fehrenbacher, J. C., Fishel, M. L. and Kelley, M. R. (2018) Exploiting the Ref-1-APE1 node in cancer signaling and other diseases: from bench to clinic. npj Precis. Oncol., 1.

224. Yuan, C. L., He, F., Ye, J. Z., et al. (2017) APE1 overexpression is associated with poor survival in patients with solid tumors: a meta-analysis. Oncotarget, 8, 59720-59728.

225. Kumar, M., Shukla, V. K., Misra, P. K. and Raman, M. J. (2018) Dysregulated expression and subcellular localization of base excision repair (BER) pathway enzymes in gallbladder cancer. Int. J. Mol. Cell. Med., 7, 119-132.

226. Di Maso, V., Mediavilla, M. G., Vascotto, C., Lupo, F., Baccarani, U., Avellini, C., Tell, G., Tiribelli, C. and Crocè, L. S. (2015) Transcriptional up-regulation of APE1/Ref-1 in hepatic tumor: role in hepatocytes resistance to oxidative stress and apoptosis. PLoS One, 10, e0143289.

227. Sun, Z., Zhu, Y., Aminbuhe, Fan, Q., Peng, J. and Zhang, N. (2018) Differential expression of APE1 in hepatocellular carcinoma and the effects on proliferation and apoptosis of cancer cells. Biosci. Trends, 12, 456-462.

228. Jiang, Y., Zhou, S., Sandusky, G. E., Kelley, M. R. and Fishel, M. L. (2010) Reduced expression of DNA repair and redox signaling protein APE1/Ref-1 impairs human pancreatic cancer cell survival, proliferation, and cell cycle progression. Cancer Invest., 28, 885-895.

229. Juhnke, M., Heumann, A., Chirico, V., et al. (2017) Apurinicl apyrimidinic endonuclease 1 (APE1/Ref-1) overexpression is an independent prognostic marker in prostate cancer without TMPRSS2:ERG fusion. Mol. Carcinog., 56, 2135-2145.

230. Hong, J., Chen, Z., Peng, D., Zaika, A., Revetta, F., Washington, M. K., Belkhiri, A. and El-Rifai, W. (2016) APE1-mediated DNA damage repair provides survival advantage for esophageal adenocarcinoma cells in response to acidic bile salts. Oncotarget, 7, 16688-16702.

231. Qing, Y., Li, Q., Ren, T., et al. (2015) Upregulation of PD-L1 and APE1 is associated with tumorigenesis and poor prognosis of gastric cancer. Drug Des. Devel. Ther., 9, 901-909.

232. Silva, L. P., Santana, T., Sedassari, B. T., de Sousa, S. M., Sobral, A. P. V., Freitas, R. A., Barboza, C. A. G. and de Souza, L. B. (2017) Apurinic/ apyrimidinic endonuclease 1 (APE1) is overexpressed in malignant transformation of salivary gland pleomorphic adenoma. Eur. Arch. Otorhinolaryngol., 274, 3203-3209.

233. Yang, X., Peng, Y., Jiang, X., et al. (2018) The regulatory role of APE1 in epithelial-to-mesenchymal transition and in determining EGFR-TKI responsiveness in non-small-cell lung cancer. Cancer Med., 7, 44064419.

234. Wen, X., Lu, R., Xie, S., Zheng, H., Wang, H., Wang, Y., Sun, J., Gao, X. and Guo, L. (2016) APE1 overexpression promotes the progression of ovarian cancer and serves as a potential therapeutic target. Cancer Biomark., 17, 313-322.

235. Sheng, Q., Zhang, Y., Wang, R., Zhang, J., Chen, B., Wang, J., Zhang, W. and Xin, X. (2012) Prognostic significance of APE1 cytoplasmic localization in human epithelial ovarian cancer. Med. Oncol., 29, 1265-1271.

236. Kakolyris, S., Kaklamanis, L., Engels, K., Turley, H., Hickson, I. D., Gatter, K. C. and Harris, A. L. (1997) Human apurinic endonuclease 1 expression in a colorectal adenoma-carcinoma sequence. Cancer Res., 57, 1794-1797.

237. Lou, D., Zhu, L., Ding, H., Dai, H. Y. and Zou, G. M. (2014) Aberrant expression of redox protein Ape1 in colon cancer stem cells. Oncol. Lett., 7, 1078-1082.

238. Noike, T., Miwa, S., Soeda, J., Kobayashi, A. and Miyagawa, S. (2008) Increased expression of thioredoxin-1, vascular endothelial growth factor, and redox factor- 1 is associated with poor prognosis in patients with liver metastasis from colorectal cancer. Hum. Pathol., 39, 201208.

239. Chen, T., Liu, C., Lu, H., Yin, M., Shao, C., Hu, X., Wu, J. and Wang, Y. (2017) The expression of APE1 in triple-negative breast cancer and its effect on drug sensitivity of olaparib. Tumour Biol., 39, 1010428317713390.

240. Abdel-Fatah, T. M., Perry, C., Moseley, P., Johnson, K., Arora, A., Chan, S., Ellis, I. O. and Madhusudan, S. (2014) Clinicopathological significance of human apurinic/apyrimidinic endonuclease 1 (APE1) expression in oestrogen-receptor-positive breast cancer. Breast Cancer Res. Treat., 143, 411-421.

241. Wang, Q., Xiao, H., Luo, Q., Li, M., Wei, S., Zhu, X., Xiao, H. and Chen, L. (2016) Low APE1/Ref-1 expression significantly correlates with MGMT promoter methylation in patients with high-grade gliomas. Int. J. Clin. Exp. Pathol., 9,9562-9568.

242. Hudson, A. L., Parker, N. R., Khong, P., et al. (2018) Glioblastoma recurrence correlates with increased APE1 and polarization toward an immuno-suppressive microenvironment. Front. Oncol., 8, 314.

243. Sengupta, S., Mantha, A. K., Song, H., Roychoudhury, S., Nath, S., Ray, S. and Bhakat, K. K. (2016) Elevated level of acetylation of APE1 in tumor cells modulates DNA damage repair. Oncotarget, 7, 75197-75209.

244. Marasco, D., Tell, G., Poletto, M., Damante, G., Loreto, C. Di., Poletto, E., and Puglisi, F. (2012) Acetylation on critical lysine residues of apurinic/apyrimidinic endonuclease 1 (APE1) in triple negative breast cancers. Biochem. Biophys. Res. Commun., 424,34-39.

245. Ding, J., Fishel, M. L., Reed, A. M., McAdams, E., Czader, M. B., Cardoso, A. A. and Kelley, M. R. (2017) Ref-1/APE1 as a transcriptional regulator and novel therapeutic target in pediatric T-cell leukemia. Mol. Cancer Ther., 16, 1401-1411.

246. Poletto, M., Malfatti, M. C., Dorjsuren, D., et al. (2016) Inhibitors of the apurinic/apyrimidinic endonuclease 1 (APE1)/nucleophosmin (NPM1) interaction that display anti-tumor properties. Mol. Carcinog., $55,688-704$.

247. Fan, X., Wen, L., Li, Y., Lou, L., Liu, W. and Zhang, J. (2017) The expression profile and prognostic value of APE/Ref-1 and NPM1 in high-grade serous ovarian adenocarcinoma. APMIS, 125, 857-862.

248. Kalitin, N. N., Chernykh, Y. B. and Buravtsova, I. V. (2017) Comparative analysis of quantitative parameters of expression of the retinoic acid nuclear receptor RAR $\alpha$ gene and APE1/YB-1/MDR1 pattern genes in patients with newly detected multiple myeloma. Bull. Exp. Biol. Med., 164, 90-94.

249. Fishel, M. L., Colvin, E. S., Luo, M., Kelley, M. R. and Robertson, K. A. (2010) Inhibition of the redox function of APE1/Ref-1 in myeloid leu- 
kemia cell lines results in a hypersensitive response to retinoic acidinduced differentiation and apoptosis. Exp. Hematol., 38, 1178-1188.

250. Abbotts, R., Jewell, R., Nsengimana, J., et al. (2014) Targeting human apurinic/apyrimidinic endonuclease 1 (APE1) in phosphatase and tensin homolog (PTEN) deficient melanoma cells for personalized therapy. Oncotarget, 5, 3273-3286.

251. Liang, W., Wei, X., Li, Q., et al. (2017) MicroRNA-765 enhances the anti-angiogenic effect of CDDP via APE1 in osteosarcoma. J. Cancer, 8, 1542-1551.

252. Dai, N., Qing, Y., Cun, Y., et al. (2018) miR-513a-5p regulates radiosensitivity of osteosarcoma by targeting human apurinic/ apyrimidinic endonuclease. Oncotarget, 9, 25414-25426.

253. Dziaman, T., Banaszkiewicz, Z., Roszkowski, K., et al. (2014) 8-Oxo7,8-dihydroguanine and uric acid as efficient predictors of survival in colon cancer patients. Int. J. Cancer, 134, 376-383.

254. Abdel-Fatah, T. M., Albarakati, N., Bowell, L., et al. (2013) Singlestrand selective monofunctional uracil-DNA glycosylase (SMUG1) deficiency is linked to aggressive breast cancer and predicts response to adjuvant therapy. Breast Cancer Res. Treat., 142, 515-527.

255. Azambuja, D. B., Leguisamo, N. M., Gloria, H. C., Kalil, A. N., Rhoden, E. and Saffi, J. (2018) Prognostic impact of changes in base excision repair machinery in sporadic colorectal cancer. Pathol. Res. Pract., 214, 64-71.

256. Lange, S. S., Takata, K. and Wood, R. D. (2011) DNA polymerases and cancer. Nat. Rev. Cancer, 11, 96-110.

257. Wang, X., Hickey, R. J., Malkas, L. H., et al. (2011) Elevated expression of cancer-associated proliferating cell nuclear antigen in high-grade prostatic intraepithelial neoplasia and prostate cancer. Prostate, 71, 748-754.

258. Malkas, L. H., Herbert, B. S., Abdel-Aziz, W., et al. (2006) A cancerassociated PCNA expressed in breast cancer has implications as a potential biomarker. Proc. Natl. Acad. Sci. U. S. A., 103, 19472-19477.

259. Abdel-Fatah, T. M., Russell, R., Albarakati, N., et al. (2014) Genomic and protein expression analysis reveals flap endonuclease 1 (FEN1) as a key biomarker in breast and ovarian cancer. Mol. Oncol., 8, 13261338 .

260. Nikolova, T., Christmann, M. and Kaina, B. (2009) FEN1 is overexpressed in testis, lung and brain tumors. Anticancer Res., 29, 2453-2459.

261. Chen, X., Legrand, A. J., Cunniffe, S., Hume, S., Poletto, M., Vaz, B., Ramadan, K., Yao, D. and Dianov, G. L. (2018) Interplay between base excision repair protein XRCC1 and ALDH2 predicts overall survival in lung and liver cancer patients. Cell. Oncol. (Dordr)., 41, 527-539.

262. Sun, D., Urrabaz, R., Nguyen, M., Marty, J., Stringer, S., Cruz, E., Medina-Gundrum, L. and Weitman, S. (2001) Elevated expression of DNA ligase I in human cancers. Clin. Cancer Res., 7, 4143-4148.

263. Wyatt, M. D. and Wilson, D. M., III. (2009) Participation of DNA repair in the response to 5-fluorouracil. Cell. Mol. Life Sci., 66, 788-799.

264. Vodenkova, S., Jiraskova, K., Urbanova, M., et al. (2018) Base excision repair capacity as a determinant of prognosis and therapy response in colon cancer patients. DNA Repair (Amst)., 72, 77-85.

265. Chaim, I. A., Nagel, Z. D., Jordan, J. J., Mazzucato, P., Ngo, L. P. and Samson, L. D. (2017) In vivo measurements of interindividual differences in DNA glycosylases and APE1 activities. Proc. Natl. Acad. Sci. U. S. A., 114, E10379-E10388.

266. Hu, J., Liu, M. H., Li, Y., Tang, B. and Zhang, C. Y. (2018) Simultaneous sensitive detection of multiple DNA glycosylases from lung cancer cells at the single-molecule level. Chem. Sci., 9, 712-720.

267. Köberle, B., Koch, B., Fischer, B. M. and Hartwig, A. (2016) Single nucleotide polymorphisms in DNA repair genes and putative cancer risk. Arch. Toxicol., 90, 2369-2388.

268. Ray, D. and Kidane, D. (2016) Gut microbiota imbalance and base excision repair dynamics in colon cancer. J. Cancer, 7, 1421-1430.

269. Kiwerska, K. and Szyfter, K. (2019) DNA repair in cancer initiation, progression, and therapy-a double-edged sword. J. Appl. Genet., 60, 329-334.

270. Liu, J., Zheng, B., Li, Y., Yuan, Y. and Xing, C. (2019) Genetic polymorphisms of DNA repair pathways in sporadic colorectal carcinogenesis. J. Cancer, 10,1417-1433.
271. Miyaishi, A., Osawa, K., Osawa, Y., et al. (2009) MUTYH Gln324His gene polymorphism and genetic susceptibility for lung cancer in a Japanese population. J. Exp. Clin. Cancer Res., 28, 10.

272. Zhang, Y., He, B. S., Pan, Y. Q., Xu, Y. Q. and Wang, S. K. (2011) Association of OGG1 Ser326Cys polymorphism with colorectal cancer risk: a meta-analysis. Int. J. Colorectal Dis., 26, 1525-1530.

273. Lai, C. Y., Hsieh, L. L., Tang, R., Santella, R. M., Chang-Chieh, C. R. and Yeh, C. C. (2016) Association between polymorphisms of APE1 and OGG1 and risk of colorectal cancer in Taiwan. World J. Gastroenterol., 22, 3372-3380.

274. Gu, D., Wang, M., Zhang, Z. and Chen, J. (2010) Lack of association between the hOGG1 Ser326Cys polymorphism and breast cancer risk: evidence from 11 case-control studies. Breast Cancer Res. Treat., 122, 527-531.

275. Ali, K., Mahjabeen, I., Sabir, M., Mehmood, H. and Kayani, M. A. (2015) OGG1 mutations and risk of female breast cancer: metaanalysis and experimental data. Dis. Markers, 2015, 690878.

276. Ramaniuk, V. P., Nikitchenko, N. V., Savina, N. V., Kuzhir, T. D., Rolevich, A. I., Krasny, S. A., Sushinsky, V. E. and Goncharova, R. I. (2014) Polymorphism of DNA repair genes OGG1, XRCC1, XPD and ERCC6 in bladder cancer in Belarus. Biomarkers, 19, 509-516.

277. Smal, M. P., Kuzhir, T. D., Savina, N. V., Nikitchenko, N. V., Rolevich, A. I., Krasny, S. A. and Goncharova, R. I. (2018) BER gene polymorphisms associated with key molecular events in bladder cancer. Exp. Oncol., 40, 288-298.

278. Stanczyk, M., Sliwinski, T., Cuchra, M., Zubowska, M., BieleckaKowalska, A., Kowalski, M., Szemraj, J., Mlynarski, W. and Majsterek, I. (2011) The association of polymorphisms in DNA base excision repair genes XRCC1, OGG1 and MUTYH with the risk of childhood acute lymphoblastic leukemia. Mol. Biol. Rep., 38, 445-451.

279. Gotoh, N., Saitoh, T., Takahashi, N., et al. (2018) Association between OGG1 S326C CC genotype and elevated relapse risk in acute myeloid leukemia. Int. J. Hematol., 108, 246-253.

280. Jiraskova, K., Hughes, D. J., Brezina, S., et al. (2019) Functional polymorphisms in DNA repair genes are associated with sporadic colorectal cancer susceptibility and clinical outcome. Int. J. Mol.Sci., 20, 97.

281. Przybylowska, K., Kabzinski, J., Sygut, A., Dziki, L., Dziki, A. and Majsterek, I. (2013) An association selected polymorphisms of XRCC1, OGG1 and MUTYH gene and the level of efficiency oxidative DNA damage repair with a risk of colorectal cancer. Mutat. Res., 745-746, 6-15.

282. Zhou, X., Wei, L., Jiao, G., Gao, W., Ying, M., Wang, N., Wang, Y. and Liu, C. (2015) The association between the APE1 Asp148Glu polymorphism and prostate cancer susceptibility: a meta-analysis based on case-control studies. Mol. Genet. Genomics, 290, 281-288.

283. Mattar, M. A. M., Zekri, A. R. N., Hussein, N., Morsy, H., Esmat, G., and Amin, M.A. (2018) Polymorphisms of base-excision repair genes and the hepatocarcinogenesis. Gene, 675,62-68.

284. Hadi, M. Z., Coleman, M. A., Fidelis, K., Mohrenweiser, H. W. and Wilson, D. M. III. (2000) Functional characterization of Ape1 variants identified in the human population. Nucleic Acids Res., 28, 3871-3879.

285. Hsieh, W. C., Lin, C., Chen, D. R., et al. (2017) Genetic polymorphisms in APE1 Asp148Glu(rs3136820) as a modifier of the background levels of abasic sites in human leukocytes derived from breast cancer patients and controls. Breast Cancer, 24, 420-426.

286. Dai, Z. J., Wang, X. J., Kang, A. J., et al. (2014) Association between APE1 single nucleotide polymorphism (rs1760944) and cancer risk: a meta-analysis based on 6,419 cancer cases and 6,781 case-free controls. J. Cancer, 5, 253-259.

287. Kiuru, A., Lindholm, C., Heinävaara, S., et al. (2008) XRCC1 and XRCC3 variants and risk of glioma and meningioma. J. Neurooncol., $88,135-142$.

288. Li, Y., Li, S., Wu, Z., et al. (2013) Polymorphisms in genes of APE1, PARP1, and XRCC1: risk and prognosis of colorectal cancer in a Northeast Chinese population. Med. Oncol., 30, 505.

289. Nissar, S., Sameer, A. S., Rasool, R., Chowdri, N. A. and Rashid, F. (2015) Polymorphism of the DNA repair gene XRCC1 (Arg194Trp) and its role in colorectal cancer in Kashmiri population: a case control study. Asian Pac. J. Cancer Prev., 16, 6385-6390. 
290. Meng, Q., Wang, S., Tang, W., et al. (2017) XRCC1 mediated the development of cervival cancer through a novel Sp1/Krox-20 swich. Oncotarget, 8, 86217-86226.

291. Sarkaria, J. N., Kitange, G. J., James, C. D., Plummer, R., Calvert, H., Weller, M. and Wick, W. (2008) Mechanisms of chemoresistance to alkylating agents in malignant glioma. Clin. Cancer Res., 14, 29002908.

292. Visnes, T., Grube, M., Hanna, B. M. F., Benitez-Buelga, C., CázaresKörner, A. and Helleday, T. (2018) Targeting BER enzymes in cancer therapy. DNA Repair (Amst)., 71, 118-126.

293. Li, B., Song, T. N., Wang, F. R., Yin, C., Li, Z., Lin, J. P., Meng, Y. Q., Feng, H. M. and Jing, T. (2019) Tumor-derived exosomal HMGB1 promotes esophageal squamous cell carcinoma progression through inducing PD1+ TAM expansion. Oncogenesis, 8, 17.

294. Gao, Q., Wang, S., Chen, X., et al. (2019) Cancer-cell-secreted CXCL11 promoted $\mathrm{CD} 8+\mathrm{T}$ cells infiltration through docetaxel-induced-release of HMGB1 in NSCLC. J. Immunother. Cancer, 7, 42.

295. Liu, Y., Prasad, R., and Wilson, S. H. (2010) HMGB1: roles in base excision repair and related function. Biochim. Biophys. Acta., 1799, 119-130.

296. Paudel, Y.N.,Angelopoulou, E.,Piperi, C., Balasubramaniam, V. R. M. T., Othman, I. and Shaikh, M. F. (2019) Enlightening the role of high mobility group box 1 (HMGB1) in inflammation: updates on receptor signalling. Eur. J. Pharmacol., 858, 172487.

297. Tang, D., Kang, R., Zeh, H. J. and Lotze, M. T. (2011) High-mobility group box 1, oxidative stress, and disease. Antioxid. Redox Signal., 14, 1315-1335.

298. Yu, Y., Tang, D. and Kang, R. (2015) Oxidative stress-mediated HMGB1 biology. Front. Physiol., 6: 93.

299. Sheller-Miller, S., Urrabaz-Garza, R., Saade, G. and Menon, R. (2017) Damage-associated molecular pattern markers HMGB1 and cell-free fetal telomere fragments in oxidative-stressed amnion epithelial cellderived exosomes. J. Reprod. Immunol., 123, 3-11.

300. Buoncervello, M., Borghi, P., Romagnoli, G., Spadaro, F., Belardelli, F., Toschi, E. and Gabriele, L. (2012) Apicidin and docetaxel combination treatment drives CTCFL expression and HMGB1 release acting as potential antitumor immune response inducers in metastatic breast cancer cells. Neoplasia, 14, 855-867.

301. Malhotra, V. (2013) Unconventional protein secretion: an evolving mechanism. ЕMBO J., 32, 1660-1664.

302. Frye, B. C., Halfter, S., Djudjaj, S., et al. (2009) Y-box protein-1 is actively secreted through a non-classical pathway and acts as an extracellular mitogen. EMBO Rep., 10, 783-789.

303. Russo, D., Arturi, F., Bulotta, S., Pellizzari, L., Filetti, S., Manzini, G., Damante, G. and Tell, G. (2001) ApeI/Ref-I expression and cellular localization in human thyroid carcinoma cell lines. J. Endocrinol. Invest., 24, RC10-RC12.

304. Bobola, M. S., Blank, A., Berger, M. S., Stevens, B. A. and Silber, J. R. (2001) Apurinic/apyrimidinic endonuclease activity is elevated in human adult gliomas. Clin. Cancer Res., 7, 3510-3518.

305. Puglisi, F., Barbone, F., Tell, G., et al. (2002) Prognostic role of Ape/ Ref-1 subcellular expression in stage I-III breast carcinomas. Oncol. Rep., 9, 11-17.
306. Bendtsen, J. D., Jensen, L. J., Blom, N., Von Heijne, G. and Brunak, S. (2004) Feature-based prediction of non-classical and leaderless protein secretion. Protein Eng. Des. Sel., 17, 349-356.

307. Park, M. S., Lee, Y. R., Choi, S., Joo, H. K., Cho, E. J., Kim, C. S., Park, J. B., Jo, E. K. and Jeon, B. H. (2013) Identification of plasma APE1/Ref-1 in lipopolysaccharide-induced endotoxemic rats: implication of serological biomarker for an endotoxemia. Biochem. Biophys. Res. Commun., 435, 621-626.

308. Choi, S., Lee, Y. R., Park, M. S., et al. (2013) Histone deacetylases inhibitor trichostatin A modulates the extracellular release of APE1/Ref1. Biochem. Biophys. Res. Commun., 435, 403-407.

309. Lee, Y. R., Kim, K. M., Jeon, B. H. and Choi, S. (2015) Extracellularly secreted APE1/Ref-1 triggers apoptosis in triple-negative breast cancer cells via RAGE binding, which is mediated through acetylation. Cancer Res., 76,4422-4422.

310. Nath, S., Roychoudhury, S., Kling, M. J., Song, H., Biswas, P., Shukla, A., Band, H., Joshi, S. and Bhakat, K. K. (2017) The extracellular role of DNA damage repair protein APE1 in regulation of IL-6 expression. Cell. Signal., 39, 18-31.

311. Pascut, D., Sukowati, C. H. C., Antoniali, G., et al. (2019) Serum AP-endonuclease 1 (sAPE1) as novel biomarker for hepatocellular carcinoma. Oncotarget, 10, 383-394.

312. Kuilman, T., Michaloglou, C., Vredeveld, L. C., Douma, S., van Doorn, R., Desmet, C. J., Aarden, L. A., Mooi, W. J. and Peeper, D. S. (2008) Oncogene-induced senescence relayed by an interleukin-dependent inflammatory network. Cell, 133, 1019-1031.

313. Tanner, K. and Gottesman, M. M. (2015) Beyond 3D culture models of cancer. Sci. Transl. Med., 7, 283 ps9.

314. Abbott, A. (2003) Cell culture: biology's new dimension. Nature, 424, 870-872.

315. Leushacke, M. and Barker, N. (2014) Ex vivo culture of the intestinal epithelium: strategies and applications. Gut, 63, 1345-1354.

316. Ohta, Y. and Sato, T. (2014) Intestinal tumor in a dish. Front. Med. (Lausanne)., 1, 14.

317. Cristobal, A., van den Toorn, H. W. P., van de Wetering, M., Clevers, H., Heck, A. J. R. and Mohammed, S. (2017) Personalized proteome profiles of healthy and tumor human colon organoids reveal both individual diversity and basic features of colorectal cancer. Cell Rep., 18, 263-274.

318. Van De Wetering, M., Francies, H. E., Francis, J. M., et al. (2015) Prospective derivation of a living organoid biobank of colorectal cancer patients. Cell, 161,933-945.

319. Drost, J., van Boxtel, R., Blokzijl, F., et al. (2017) Use of CRISPRmodified human stem cell organoids to study the origin of mutational signatures in cancer. Science, 358, 234-238.

320. Francies, H. E., Barthorpe, A., McLaren-Douglas, A., Barendt, W. J. and Garnett, M. J. (2019) Erratum to: drug sensitivity assays of human cancer organoid cultures. Methods Mol. Biol., 1576, 353.

321. Codrich, M., Comelli, M., Malfatti, M. C., et al. (2019) Inhibition of APE1-endonuclease activity affects cell metabolism in colon cancer cells via a p53-dependent pathway. DNA Repair (Amst)., 82, 102675.

322. Li, T., Wernersson, R., Hansen, R. B., et al. (2017) A scored human protein-protein interaction network to catalyze genomic interpretation. Nat. Methods, 14, 61-64. 